\title{
The PNPLA3-I148M Variant Confers an Antiatherogenic Lipid Profile in Insulin-resistant Patients
}

\section{Luukkonen, Panu K.}

2021-01

Luukkonen, P K , Qadri , S , Lehtimäki , T E , Juuti , A, Sammalkorpi , H , Penttilä , A K , Hakkarainen, A , Orho-Melander , M , Arola , J \& Yki-Järvinen , H 2021 , ' The

PNPLA3-I148M Variant Confers an Antiatherogenic Lipid Profile in Insulin-resistant Patients ' , Journal of Clinical Endocrinology and Metabolism , vol. 106 , no. 1 , pp. e300-e315 . https://doi.org/10.1210/clinem/

http://hdl.handle.net/10138/338159

https://doi.org/10.1210/clinem/dgaa729

unspecified

acceptedVersion

Downloaded from Helda, University of Helsinki institutional repository.

This is an electronic reprint of the original article.

This reprint may differ from the original in pagination and typographic detail.

Please cite the original version. 
The PNPLA3-I148M variant confers an antiatherogenic lipid profile in insulin-resistant patients

Panu K. Luukkonen ${ }^{1,2,3^{*}}$, Sami Qadri ${ }^{1,2^{*}}$, Tiina E. Lehtimäki ${ }^{4}$, Anne Juuti ${ }^{5}$, Henna Sammalkorpi ${ }^{5}$, Anne K. Penttilä ${ }^{5}$, Antti Hakkarainen ${ }^{4}$, Marju Orho-Melander ${ }^{6}$, Johanna Arola ${ }^{7}$, Hannele Yki-Järvinen ${ }^{1,2}$

${ }^{1}$ Department of Medicine, University of Helsinki and Helsinki University Hospital, Helsinki, Finland; ${ }^{2}$ Minerva Foundation Institute for Medical Research, Helsinki, Finland;

${ }^{3}$ Yale School of Medicine, Yale University, New Haven, CT, USA;

${ }^{4}$ HUS Medical Imaging Center, Helsinki University Hospital, Helsinki, Finland;

${ }^{5}$ Department of Gastrointestinal Surgery, Abdominal Center, Helsinki University Hospital, Helsinki, Finland;

${ }^{6}$ Department of Clinical Sciences Malmö, Lund University, Malmö, Sweden;

${ }^{7}$ Department of Pathology, University of Helsinki and Helsinki University Hospital, Helsinki, Finland.

* = equal contribution

Running title: PNPLA3-I148M, lipids and insulin resistance

Keywords: metabolic syndrome, insulin resistance, dyslipidemia, patatin-like phospholipase domain containing 3, non-alcoholic fatty liver disease, lipoproteins

Corresponding author: Hannele Yki-Järvinen, MD, FRCP, Biomedicum Helsinki 1, Room A418a, Haartmaninkatu 8, 00290 Helsinki, Finland. Phone: +358-50 562 6899, e-mail: hannele.ykijarvinen@helsinki.fi 
Reprint requests: Hannele Yki-Järvinen, MD, FRCP, Biomedicum Helsinki 1, Room A418a, Haartmaninkatu 8, 00290 Helsinki, Finland. Phone: +358-50 562 6899, e-mail: hannele.ykijarvinen@helsinki.fi

\section{Funding statement}

This study was supported by the Academy of Finland grant no. 309263 (HY-J); the EU H2020 project 'Elucidating Pathways of Steatohepatitis' (EPOS) grant no. 634413 (HY-J); the H2020-JTI-IMI2 EU project 777377-2 'Liver Investigation: Testing Marker Utility in Steatohepatitis' (LITMUS) (HY-J); the Sigrid Jusélius Foundation (HY-J, PKL), Erityisvaltionosuus (EVO) (HY-J); the Instrumentarium Science Foundation (PKL); and the Novo Nordisk Foundation (HY-J, PKL).

\section{Disclosure statement}

The authors have nothing to disclose. 


\section{ABSTRACT}

Context: The I148M (rs738409-G) variant in PNPLA3 increases liver fat content but may be protective against cardiovascular disease. Insulin resistance (IR) amplifies the effect of PNPLA3-I148M on liver fat.

Objective: To study whether PNPLA3-I148M confers an antihyperlipidemic effect in insulin-resistant patients.

Design: Cross-sectional study comparing the impact of PNPLA3-I148M on plasma lipids and lipoproteins in two cohorts, both divided into groups based on rs738409-G allele carrier status and median HOMA-IR.

Setting: Tertiary referral center.

Patients: 298 obese patients who underwent a liver biopsy during bariatric surgery (Bariatric cohort; age $49 \pm 9$ years, $\mathrm{BMI} 43.2 \pm 6.8 \mathrm{~kg} / \mathrm{m}^{2}$ ), and 345 less obese volunteers in whom liver fat was measured by proton magnetic resonance spectroscopy (Non-bariatric cohort; age $45 \pm 14$ years, BMI $29.7 \pm 5.7$ $\left.\mathrm{kg} / \mathrm{m}^{2}\right)$.

Main Outcome Measures: Nuclear magnetic resonance profiling of plasma lipids, lipoprotein particle subclasses and their composition.

Results: In both cohorts, individuals carrying the PNPLA3-I148M variant had significantly higher liver fat content than non-carriers. In insulin-resistant and homozygous carriers, PNPLA3-I148M exerted a distinct antihyperlipidemic effect with decreased very-low-density lipoprotein (VLDL) and low-density lipoprotein particles (LDL) and their constituents, and increased high-density lipoprotein particles and their constituents, as compared to non-carriers. VLDL particles were smaller and LDL particles larger in PNPLA3-I148M carriers. These changes were geometrically opposite to those due to IR. PNPLA3I148M did not have a measurable effect in patients with lower IR, and its effect was smaller albeit still significant in the less obese compared to the obese cohort. 
Conclusions: PNPLA3-I148M confers an antiatherogenic plasma lipid profile particularly in insulinresistant individuals. 


\section{INTRODUCTION}

Cardiovascular disease (CVD) is the leading cause of death in patients with nonalcoholic fatty liver disease (NAFLD) (1), which usually coexists with the metabolic/insulin resistance (IR) syndrome (2). In this "Metabolic NAFLD", IR impairs the ability of insulin to suppress hepatic production of glucose and triglyceride (TG)-rich very-low-density lipoprotein (VLDL) particles (2), manifesting clinically as hyperglycemia and atherogenic dyslipidemia (3). The increased risk of CVD in NAFLD is considered to be the consequence of atherogenic dyslipidemia, rather than of steatosis itself (4). However, NAFLD is heterogenous and not uniformly associated with dyslipidemia and an increased risk of CVD. The best example of this is NAFLD caused by the E167K (rs58542926-T) gene variant in transmembrane 6 superfamily member 2 (TM6SF2), which decreases plasma TG (5-8), cholesterol (8-10) and apoB $(7,11)$ concentrations and the risk of myocardial infarction (9), cardiovascular events and atherosclerotic plaques (7).

The I148M variant ( $r 5738409$, c.444C $>$ G) in patatin-like phospholipase domain containing 3 (PNPLA3) is common (prevalence $30-50 \%$ worldwide $(12,13)$ ) and the most important genetic risk factor for NAFLD. It significantly increases liver fat content (i.e. intrahepatic triglycerides [IHTGs]) and predisposes variant carriers to advanced liver disease $(14,15)$, while simultaneously dissociating the NAFLD-phenotype from IR $(14,16)$. Consistent with this dissociation, large-scale genomic studies have associated the PNPLA3-I148M variant with a lower risk of CVD (17-19).

PNPLA3 is a lipid droplet protein that is thought to facilitate transacylation of polyunsaturated fatty acids (PUFAs) from TGs or diacylglycerols (DAGs) to phosphatidylcholines (PCs) $(20,21)$. In the human liver, PNPLA3-I148M confers a similar phenotype as in mice expressing the catalytically inactive PNPLA3-S47A variant $(20,21)$, causing retention of PUFAs in IHTGs, with a concomitant deficiency of 
PUFAs in hepatic PCs and in circulating VLDL (21). Since PUFA-PCs are required for successful lipidation of VLDL particles in the liver (22), PNPLA3-I148M could be predicted to decrease plasma TG concentrations by reducing the mobilization of fatty acids from IHTGs, or by impairing VLDL lipidation via deficiency of PUFA-PCs. However, contrary to expectations, studies which have examined the association between PNPLA3-I148M and circulating lipoproteins have not shown the variant to induce changes in lipids or lipoproteins $(23,24)$. In a population-based study with 1,810 individuals aged 34-49 years, the PNPLA3-I148M variant had no effect on plasma lipoproteins (23). Another study, which examined lipoprotein compositions in 170 patients with NAFLD, found no associations between I148M variant carrier status and concentrations of lipoprotein particles (24).

The degree to which PNPLA3-I148M increases IHTG content is greatly amplified by adiposity (25) and, perhaps even more so, by IR $(16,26)$. In normal-weight/insulin-sensitive individuals, the I148M variant induces only a negligible increase in IHTGs $(16,26)$. This raises the possibility that IR may be required to unmask antiatherogenic effects of PNPLA3-I148M on circulating lipids and lipoproteins. This hypothesis was tested in the present study. To this end, we studied the impact of the PNPLA3-I148M gene variant and IR on plasma lipids and lipoproteins using nuclear magnetic resonance (NMR) -based metabolomics in a cohort of 298 severely obese individuals. The results were replicated in a separate cohort consisting of 345 individuals who were less obese. For comparison, we also analyzed the impact of the TM6SF2-E167K variant on plasma lipids and lipoproteins. 


\section{MATERIALS AND METHODS}

\section{Patients}

NMR profiling of plasma lipids and lipoprotein particles was performed in two separate cohorts comprising a total of 643 patients who fulfilled the inclusion and exclusion criteria (vide infra). Of these, 298 patients were morbidly obese and were studied consecutively prior to undergoing laparoscopic bariatric surgery at the Helsinki University Hospital (Helsinki, Finland), referred to as the Bariatric cohort. The other 345 leaner volunteers did not undergo surgery and are referred to as the Non-bariatric cohort. Inclusion criteria included: (i) age 18 to 75 years; (ii) alcohol consumption less than $20 \mathrm{~g}$ per day for females and less than $30 \mathrm{~g}$ per day for males. Exclusion criteria included: (i) known acute or chronic diseases other than obesity, type 2 diabetes, NAFLD or hypertension on the basis of medical history, physical examination and standard laboratory tests (complete blood counts, serum creatinine and electrolyte concentrations); (ii) clinical or biochemical evidence of liver disease other than NAFLD, or clinical signs or symptoms of inborn errors of metabolism; (iii) history or current use of toxins or drugs associated with hepatic steatosis, (iv) pregnancy or lactation. The study protocols were approved by the ethics committee of the Hospital District of Helsinki and Uusimaa (Helsinki, Finland). The study was conducted in accordance with the Declaration of Helsinki. Each participant provided a written informed consent after being explained the nature and potential risks of the study.

\section{Study design}

All patients arrived at the Clinical Research Unit after an overnight fast (a week before surgery for the Bariatric cohort). A history and physical examination were performed to review the inclusion and exclusion criteria. Weight, height, waist circumference and blood pressure (BP) were measured as previously described (27). Blood samples were taken for measurement of plasma lipids and 
lipoproteins using NMR profiling (vide infra). In addition, blood samples were taken for measurement of blood counts, glucose, glycosylated hemoglobin $A_{1 c}\left(H_{b A_{1 c}}\right)$, insulin, non-esterified fatty acids (NEFAs), HDL and LDL cholesterol, TG, alanine aminotransferase (ALT), aspartate aminotransferase (AST), gamma-glutamyl transferase (GGT) and albumin concentrations, and for genotyping of NAFLDassociated alleles PNPLA3 rs738409 (14), TM6SF2 rs58542926 (5), MBOAT7 rs641738 (28) and HSD17B13 rs72613567 (29) as previously described (16,30-32). The Bariatric cohort underwent a wedge biopsy of the liver at the beginning of the laparoscopic bariatric surgery. Histologic analysis of the biopsy was performed by the same pathologist (J.A.) using the SAF score (33). The patients in the Non-bariatric cohort underwent measurement of their IHTG content using proton magnetic resonance spectroscopy $\left({ }^{1} \mathrm{H}-\mathrm{MRS}\right)$ (vide infra) within a week after the Clinical Research Unit visit.

We analyzed the effects of PNPLA3-I148M and IR on plasma lipid and lipoprotein composition in the Bariatric cohort and Non-bariatric cohort separately. To this end, patients in both cohorts were divided into subgroups on the basis of their carrier status for the PNPLA3 rs738409 C>G allele ("PNPLA3 CC" or "PNPLA3 CG/GG") and IR as determined by homeostasis model assessment of insulin resistance (HOMA-IR), derived by using the formula: HOMA-IR $=$ fS-insulin $(\mathrm{mU} / \mathrm{L}) \times \mathrm{fP}$-glucose (mmol/L) / 22.5 (34). The sex-specific median HOMA-IR was used as the cut-off value for dividing the patients in both cohorts into two equally sized groups differing with respect to insulin sensitivity. Patients with HOMA-IR at or above this cut-off value (Bariatric cohort, males $\geq 4.20$ and females $\geq 3.04$; Non-bariatric cohort, males $\geq 1.97$ and females $\geq 1.66$ ) were assigned to the "High HOMA-IR" group, while patients with HOMA-IR below the cut-off value were assigned to the "Low HOMA-IR" group. Of importance, the term "Low HOMA-IR" only refers to variation inside the cohort, as in the Bariatric cohort most of the patients had HOMA-IR values higher than 95\% of the population (35). As we 
wanted to analyze the effect of IR on plasma lipoproteins separately from effects of the PNPLA3I148M variant, patients in the HOMA-IR subgroups all had the CC genotype.

NMR profiling of lipoprotein subclasses and their composition

A high-throughput NMR platform (AVANCE III $500 \mathrm{MHz}$ and AVANCE III $600 \mathrm{MHz}$, Bruker, Karlsruhe, Germany) was used for the quantification of lipids and lipoproteins from plasma samples (36). These included concentrations and sizes of lipoprotein particles as well as concentrations of total lipids, TGs, phospholipids, total cholesterol, esterified cholesterol and free cholesterol in 14 lipoprotein subclasses, and concentrations of apolipoproteins A1 and B, as described in (36).

The quantified lipoprotein subfractions and average particle diameters are as follows: extremely large very-low-density lipoprotein (XXL-VLDL, >75 nm); very large very-low-density lipoprotein (XL-VLDL, $64.0 \mathrm{~nm}$ ); large very-low-density lipoprotein (L-VLDL, $53.6 \mathrm{~nm})$; medium very-low-density lipoprotein (M-VLDL, $44.5 \mathrm{~nm}$ ); small very-low-density lipoprotein (S-VLDL, $36.8 \mathrm{~nm}$ ); very small very-low-density lipoprotein (XS-VLDL, $31.3 \mathrm{~nm}$ ); intermediate-density lipoprotein (IDL, $28.6 \mathrm{~nm}$ ); large low-density lipoprotein (L-LDL, $25.5 \mathrm{~nm}$ ); medium low-density lipoprotein (M-LDL, $32.0 \mathrm{~nm}$ ); small low-density lipoprotein (S-LDL, $18.7 \mathrm{~nm}$ ); very large high-density lipoprotein (XL-HDL, $14.3 \mathrm{~nm}$ ); large high-density lipoprotein (L-HDL, $12.1 \mathrm{~nm}$ ); medium high-density lipoprotein (M-HDL, $10.9 \mathrm{~nm}$ ); small high-density lipoprotein (S-HDL, $8.7 \mathrm{~nm}$ ) (36).

\section{Measurement of IHTG content by ${ }^{1} H-M R S$}

In Non-bariatric cohort patients in whom liver biopsy was not obtained, IHTG content was measured by ${ }^{1} \mathrm{H}-\mathrm{MRS}$ using the $1.5 \mathrm{~T}$ MAGNETOM Avanto fit magnetic resonance imaging scanner (Siemens Healthcare $\mathrm{GmbH}$, Erlangen, Germany) as previously described in detail (27). In brief, magnetic 
resonance spectra were acquired using a point resolved spectroscopy sequence with a repetition time (TR) of 3,000 ms and an echo time (TE) of 20 ms and quantified using jMRUI v5.2 software (37) with the AMARES algorithm (38). Resonances of methylene groups in the FA chains and water were determined using line-shape fitting with prior knowledge. IHTG content was expressed as a ratio of signal from methylene groups to total signal of methylene and water, and converted from signal ratio to a weight fraction, applying the methods validated by Longo et al. (39) and Szczepaniak et al. (40).

\section{Other analytical procedures from human samples}

Fasting plasma glucose was measured using the hexokinase method on an autoanalyzer (Roche Diagnostics Hitachi 917, Hitachi Ltd., Tokyo, Japan). Serum insulin concentration was determined by time-resolved fluoroimmunoassay using the Insulin Kit (AUTOdelfia, Wallac, Turku, Finland). HbA $1 c$ was measured with an immunoturbidometric method (Abbott Laboratories) and plasma ALT, AST, and GGT activities using photometric International Federation of Clinical Chemistry methods (Abbott Laboratories). Plasma TG, total cholesterol, LDL and HDL cholesterol concentrations were measured using enzymatic kits and an autoanalyzer (Roche Diagnostics Hitachi 917, Hitachi Ltd., Tokyo, Japan). Plasma NEFAs were measured by using an enzymatic colorimetric assay (NEFA-HR(2); Wako Chemicals GmbH, Neuss, Germany) with a Konelab 60i analyzer (Thermo Electron Corporation, Vantaa, Finland). Adipo-IR, a surrogate for adipose tissue IR, was calculated using the formula: fSinsulin (mU/L) × fP-NEFA (mmol/L) (41). Plasma albumin was measured using a photometric method on an autoanalyzer (Modular Analytics EVO; Hitachi High-Technologies Corporation, Tokyo, Japan).

\section{Statistical analyses}

Statistical analyses were performed using Microsoft Excel for Mac 16.35 (Microsoft, Redmond, WA), GraphPad Prism 8.1.2 for Mac OS X (GraphPad Software, La Jolla, CA), and R version 3.6.0 (R 
Foundation for Statistical Computing, Vienna, Austria). Missing NMR-metabolomic data were imputed by random forest imputation using the R package "missForest" $(42,43)$. None of the variables had over $30 \%$ missingness. Univariate normality was determined using the KolmogorovSmirnov test. Non-normally distributed variables were log-transformed for analysis and backtransformed for display. Data are reported in either means \pm standard deviations (SD), medians [ $25^{\text {th }}$ $75^{\text {th }}$ percentiles], or in numbers $(n)$ and percentages (\%). The unpaired Student's $t$-test or the MannWhitney $U$ test were used to compare continuous data and the Pearson's $\chi^{2}$ test was used to compare categorical data. For studying of the effects of PNPLA3 rs738409-G and TM6SF2 rs58542926-T alleles in HOMA-IR subgroups in the Bariatric cohort, binary logistic regression analysis was used with the genotype (carrier vs. non-carrier) as the dependent variable and NMR-quantified measures as independent variables. The models were adjusted for age, sex, BMI, and smoking status ( \pm use of statins), and results are displayed as odds ratios (OR) [95\% confidence intervals] per unit change in SD to enable cross-variable comparison. A P-value of less than 0.05 was considered to be statistically significant. 


\section{RESULTS}

\section{Patient characteristics}

Clinical characteristics of the HOMA-IR and PNPLA3 genotype subgroups in the Bariatric cohort are shown in Table 1. In the whole cohort, mean age was $49 \pm 9$ years, mean BMI $43.2 \pm 6.8 \mathrm{~kg} / \mathrm{m}^{2}$, and median HOMA-IR 3.36 [2.01-4.92]. Genotype distributions did not deviate from Hardy-Weinberg equilibrium. The subgroups were similar with respect to the distribution of NAFLD risk alleles in TM6SF2, MBOAT7, and HSD17B13 genes (Table 1). The "High HOMA-IR" group had significantly more type 2 diabetes and a higher BMI $\left(44.3 \pm 6.2\right.$ vs. $\left.40.8 \pm 6.1 \mathrm{~kg} / \mathrm{m}^{2}, P<0.001\right)$ and waist circumference, higher concentrations of serum insulin and higher HOMA-IR, ALT and plasma TGs than the "Low HOMA-IR" group (Table 1). The "High HOMA-IR" group also had higher IHTG content (13 [5-33] vs. 0 $[0-10] \%, P<0.001)$ and SAF score $(2.1 \pm 2.0$ vs. $1.0 \pm 1.5, P<0.001)$, which is a composite histological score of steatosis, necroinflammatory activity and fibrosis, as compared to the "Low HOMA-IR" group (Table 1).

The PNPLA3 subgroups were similar with respect to age, sex, BMI, plasma glucose, $\mathrm{HbA}_{1 \mathrm{c}}$, serum insulin, HOMA-IR, plasma lipids, liver enzymes, presence of type 2 diabetes, smoking status, and use of medications (Table 1). The "PNPLA3 CG/GG" group had higher IHTG content (15 [0-30] vs. 5 [0-20] $\%, P<0.05)$ and SAF score (2.0 \pm 2.0 vs. $1.6 \pm 1.9, P<0.05)$ than the "PNPLA3 CC" group (Table 1$)$.

\section{Opposing effects of IR and PNPLA3-I148M on plasma lipoproteins}

The distribution of serum TG and cholesterol content within plasma lipoprotein subfractions in the Bariatric cohort is shown in Figure 1. Comparison of the NMR-composition of plasma lipoprotein subclasses between the HOMA-IR groups in the Bariatric cohort is shown in Figure 2 (left panel). The number of XXL-, XL-, L-, M-, and S-VLDL particles as well as M-LDL particles and their constituents, 
including total lipids, phospholipids, total cholesterol, cholesterol esters, free cholesterol and triglycerides, were significantly higher in the "High HOMA-IR" group than in the "Low HOMA-IR" group (Figure 2). Triglycerides were also significantly higher in XS-VLDL and S-HDL particles in the "High HOMA-IR" as compared to the "Low HOMA-IR" group (Figure 2). On the contrary, the number of $M-$, L- and XL-HDL particles and their constituents were significantly lower in the "High HOMA-IR" group than in the "Low HOMA-IR" group (Figure 2). The mean diameter of VLDL particles $(39.83 \pm 1.55$ vs. $38.71 \pm 1.77 \mathrm{~nm}, P<0.001)$ was significantly larger while those of LDL $(24.48 \pm 0.19$ vs. $24.55 \pm 0.18$ $\mathrm{nm}, P<0.001)$ and HDL particles $(9.38 \pm 0.12$ vs. $9.51 \pm 0.18 \mathrm{~nm}, P<0.001)$ were significantly smaller in the "High HOMA-IR" as compared to the "Low HOMA-IR" group. The apolipoprotein B (apoB) to apolipoprotein A-1 (apoA-1) ratio was significantly higher ( $0.64 \pm 0.12$ vs. $0.57 \pm 0.12, P<0.001)$ in the "High HOMA-IR" as compared to the "Low HOMA-IR" group.

Comparison of lipoprotein subclasses between the "PNPLA3 CC" and "PNPLA3 CG/GG" groups yielded unremarkable results (Figure 2, middle panel). This finding is in line with previous reports where no changes in lipoprotein subfraction concentrations with regard to carrier status of rs738409G were observed $(23,24)$. We next grouped the patients based on homozygosity for the rs738409-G allele in PNPLA3 ("PNPLA3 CC" and "PNPLA3 GG") to test whether two variant alleles are required for an effect. The resulting groups were similar with respect to age, sex, BMI, plasma glucose, $\mathrm{HbA}_{1 \mathrm{c}}$, serum insulin, HOMA-IR, liver enzymes, plasma cholesterol concentrations, presence of type 2 diabetes, use of medications, and smoking status (Table 2). Plasma triglycerides were significantly lower (1.12 [1.03-1.34] vs. $1.23[0.88-1.61] \mathrm{mmol} / \mathrm{L}, P<0.05)$ and the SAF score was higher $(2.6 \pm 2.3$ vs. 1.6 $\pm 1.9, P<0.05)$ in the "PNPLA3 GG" group as compared to the "PNPLA3 CC" group (Table 2). 
Changes in lipoprotein subclasses in the "PNPLA3 GG" as compared to the "PNPLA3 CC" group were virtually opposite and comparable in magnitude to those observed in the "High HOMA-IR" versus the "Low HOMA-IR" group (Figure 2, right panel). The number of XXL-, XL-, L-, and M-VLDL particles and most of their constituents as well as M-LDL particles and their constituents were significantly lower, while the number of L-HDL particles and their constituents was significantly higher in the "PNPLA3 GG" group as compared to the "PNPLA3 CC" group (Figure 2). The mean diameter of VLDL (38.6 \pm 1.0 vs. $39.3 \pm 1.8 \mathrm{~nm}, P<0.05)$ particles was also significantly smaller while that of LDL $(24.59 \pm 0.12$ vs. $24.51 \pm 0.19 \mathrm{~nm}, P<0.05)$ particles was significantly larger in the "PNPLA3 GG" group compared to the "PNPLA3 CC" group. The apoB to apoA-1 ratio was significantly lower $(0.55 \pm 0.09$ vs. 0.61 \pm 0.12 , $P<0.05)$ in the "PNPLA3 GG" group as compared to the "PNPLA3 CC" group.

\section{The effect of PNPLA3-I148M on plasma lipoproteins is less pronounced in leaner patients}

We replicated the above analysis in an independent cohort consisting of non-morbidly obese and less insulin-resistant patients who did not undergo bariatric surgery (Non-bariatric cohort) using the same NMR methodology. At the level of the whole cohort, mean age was $45 \pm 14$ years, mean BMI $29.7 \pm 5.7$ $\mathrm{kg} / \mathrm{m}^{2}$, and median HOMA-IR 1.64 [0.92-2.82]. Genotype distributions did not deviate from HardyWeinberg equilibrium. The subgroups were similar with respect to the distribution of NAFLD risk alleles in TM6SF2, MBOAT7, and HSD17B13 genes (Table 3). The "High HOMA-IR" group was older (46 \pm 14 vs. $41 \pm 13$ years, $P<0.01)$ and had significantly higher BMI $\left(32.5 \pm 5\right.$ vs. $\left.27.0 \pm 4 \mathrm{~kg} / \mathrm{m}^{2}, P<0.001\right)$, waist circumference, systolic BP, liver enzymes, plasma glucose, $\mathrm{HbA}_{1 \mathrm{c}}$, serum insulin, NEFA, AdipoIR, HOMA-IR, TGs, total and LDL cholesterol, and lower HDL cholesterol concentrations as compared to the "Low HOMA-IR" group (Table 3). The "High HOMA-IR" group also had higher IHTG content by ${ }^{1} \mathrm{H}-\mathrm{MRS}(5.4$ [2.9-10.7] vs. 1.0 [0.4-2.2] \%, P<0.001) than the "Low HOMA-IR" group (Table 3). The "PNPLA3 CC" and "PNPLA3 GG" groups were similar with respect to age, sex, BMI, plasma glucose, 
$\mathrm{HbA}_{1 \mathrm{C}}$, serum insulin, HOMA-IR, NEFA, Adipo-IR, plasma lipids, presence of type 2 diabetes, smoking status, and use of medications (Table 3). The "PNPLA3 GG" group had higher ALT and AST levels, and higher IHTG content (9.1 [4.3-13.1] vs. $2.7(0.8-6.1) \%, P<0.001)$ as compared to the "PNPLA3 CC" group (Table 3).

The distribution of serum TG and cholesterol content within plasma lipoprotein subfractions in the Non-bariatric cohort is shown in Figure 3. Similar to results in the Bariatric cohort (Figure 2), the "High HOMA-IR" group in the Non-bariatric cohort had significantly higher concentrations of all subclasses of VLDL, IDL and LDL particles and most of their lipid constituents, and lower concentrations M-, Land XL-HDL particles and their constituents, as compared to the "Low HOMA-IR" group (Figure 4, left panel). Differences in lipid profiles between the "High HOMA-IR" and "Low HOMA-IR" groups persisted after adjusting for age (data not shown). Like in the Bariatric cohort, we did not find significant differences in circulating lipoproteins between the "PNPLA3 CG/GG" and "PNPLA3 GG" groups (not shown). However, after excluding heterozygous variant carriers ( $n=143)$, the "PNPLA3 GG" group had significantly lower concentrations of XXL- and XL-VLDL particles and their constituents, as well as lower TG content in S-LDL particles, as compared to the "PNPLA3 CC" group

(Figure 4, right panel). The "PNPLA3 GG" group had also a significantly smaller diameter of VLDL (38.6 \pm 1.1 vs. $39.1 \pm 1.9 \mathrm{~nm}, P<0.05)$ particles and a significantly larger diameter of $L D L(24.64 \pm 0.12$ vs. $24.57 \pm 0.20 \mathrm{~nm}, P<0.01)$ particles as compared to the "PNPLA3 CC" group.

Insulin resistance amplifies the antihyperlipidemic effect of PNPLA3-I148M, similarly to that of the TM6SF2-E167K variant

The above data suggest that PNPLA3-I148M opposes the effects of severe IR on the number and composition of circulating lipoprotein particles, and that this effect is apparent particularly in 
homozygous carriers of the variant. However, despite similar sample size, the effect of PNPLA3I148M on lipoproteins was stronger in the Bariatric cohort (Figure 2) with more severely insulinresistant patients than in the Non-bariatric cohort (Figure 4), which consisted of leaner patients.

To determine whether IR interacts with PNPLA3-I148M, we first analyzed the effects of the rs738409$\mathrm{G}$ allele on lipoproteins by dividing all patients in the Bariatric cohort into two groups based on median HOMA-IR ("High HOMA-IR" and "Low HOMA-IR"). We excluded patients on statin therapy $(n=88)$ from this analysis. Using a binary logistic regression model adjusted for age, sex, BMI, and smoking status, we did not see any significant associations between the rs738409-G allele and circulating lipoproteins in the "Low HOMA-IR" group (Figure 5, first panel). On the contrary, in the "High HOMA-IR" group, the variant allele predicted significantly lower concentrations of XL-, L-, $M-$ VLDL and M- and S-LDL particles, higher concentrations of $\mathrm{M}-$, $\mathrm{L}$ - and $\mathrm{XL}-\mathrm{HDL}$ particles, as well as a smaller diameter of VLDL particles and larger diameter of HDL particles, higher cholesterol content in $\mathrm{HDL}$ particles, and higher concentrations of apoA-1 and lower concentrations of apoB apolipoproteins (Figure 5, second panel). Thus, high IR appears to be required to unmask the antihyperlipidemic effects of PNPLA3-I148M.

For comparison, we analyzed how the TM6SF2-E167K variant interacts with IR in the Bariatric cohort. Using a binary logistic regression model adjusted for age, sex, BMI, and smoking status, we did not observe any significant associations between the rs58542926-T allele and circulating lipoproteins in the "Low HOMA-IR" group (Figure 5, third panel). However, in the "High HOMA-IR" group, the T-allele predicted significantly lower concentrations of L-, M-, S-, and XS-VLDL particles, lower TG-content in VLDL and LDL particles, and higher concentrations of L-HDL particles (Figure 3, fourth panel). These 
results resemble those of PNPLA3-I148M and suggest a similar synergistic interaction between the TM6SF2-E167K variant and IR.

To determine whether there exists a threshold level of HOMA-IR above which PNPLA3-I148M most significantly affects lipids, we next pooled all of the study patients $(n=643)$ and divided them into quartiles based on HOMA-IR. Adjusted for age, sex, BMI, smoking status and use of statins, the rs738409-G allele did not exert statistically significant changes on lipids in the first three quartiles (Figure 6, first three panels). In the highest quartile with HOMA-IR above 3.96 (median 5.50 [4.657.58]), the variant predicted significantly lower concentrations of XL-VLDL, L-VLDL, M-LDL and S-LDL particles and a higher concentration of L-HDL particles, lower diameter of VLDL and higher diameter of HDL particles, lower TG content in VLDL, lower cholesterol content in LDL, and lower apoB to apoA1 ratio (Figure 6, last panel). 


\section{DISCUSSION}

We investigated whether insulin-resistant carriers of the PNPLA3-I148M variant have a less atherogenic plasma lipoprotein composition compared to non-carriers, as could be hypothesized based on recent mechanistic studies addressing PNPLA3 function $(16,20)$. We found homozygous I148M variant carriers to have consistently lower plasma levels of especially VLDL particles and their lipid constituents, and higher levels of HDL particles and their constituents, as compared to noncarriers. The effect of PNPLA3-I148M on lipids and lipoproteins was virtually a mirror-image of the typical atherogenic dyslipidemia of insulin-resistant patients. This effect was observed in two independent cohorts, which included a Bariatric cohort with morbidly obese individuals and a less obese Non-bariatric cohort.

Advances in NMR methodology have resulted in the development of a platform which enables rapid and accurate profiling of plasma lipoprotein subclasses and their size and composition, without timeand labor-intensive ultracentrifugation techniques (36). This technology allowed us to perform comprehensive lipid and lipoprotein profiling in two relatively large independent groups, which were both divided into subgroups based on PNPLA3 genotype at rs738409 and sex-specific median HOMAIR. A similar approach was previously used to document that the liver lipidome in subjects with NAFLD due to the PNPLA3-I148M variant is markedly different from that in subjects with NAFLD due to IR (16). The median HOMA-IR of patients in the Bariatric cohort was over 3, which is higher than the upper limit of normal of approximately 2 for NAFLD, defined as IHTG content exceeding $5.55 \%$ by ${ }^{1} \mathrm{H}$ MRS $(35,44)$. Thus, naming of the "Low HOMA-IR" group in this study is a bit of a misnomer.

Despite large patient cohorts, previous studies that have investigated the impact of PNPLA3 rs738409-G carrier status on plasma lipoprotein composition have produced negative results $(23,24)$. 
Of note, these studies recruited lean and healthy individuals and lacked the comparison of homozygous G-allele carriers to non-carriers. These findings were confirmed in the present study in which the PNPLA3-I148M variant had no discernible effect on lipids and lipoproteins in individuals classified as "Low HOMA-IR" (Figure 5). Also, the variant appeared to modulate lipids to a smaller extent in the less obese Non-bariatric cohort than in the severely obese Bariatric cohort (Figures 2 and 4), in keeping with data of Palmer et al. in morbidly obese subjects in the Swedish Obese Subjects study (45). The dependence of the lipid-altering effects of PNPLA3-I148M on IR is similar to that previously described for liver fat, which is most apparent in obese and insulin-resistant homozygous carriers $(16,25,26)$. The I148M variant significantly affected lipids only in the highest quartile of HOMA-IR, which included subjects with an HOMA-IR greater than 4 in the pooled cohort (Figure 6).

Regarding the mechanism underlying the effect of the PNPLA3-I148M variant on circulating lipids, we have previously shown that the human liver of PNPLA3-I148M carriers is deficient in PUFA-PCS compared to non-carriers (21). PUFA-PCs are important for lipoprotein formation and stability as they form a monolayer around the neutral lipid core consisting of TGs and cholesteryl esters (22). VLDL particles are assembled in the endoplasmic reticulum (ER) in hepatocytes, a process beginning with translation of apoB on ER-bound ribosomes, which is then lipidated in the ER lumen (22). PCs located in the ER membrane are incorporated into nascent VLDL particles, and a deficiency of PC leads to premature degradation of VLDL (22). The results of the present study are consistent with relative deficiency of hepatic PCs in I148M variant carriers, which could contribute to the reduced hepatic VLDL secretion seen in these patients (Figures 2, 4, 5 and 6) (46).

The TM6SF2-E167K variant reduces hepatic VLDL secretion by impairing particle formation and lipidation (11,47-49) and is known to induce antiatherogenic changes in plasma lipids and 
lipoproteins $(5-8,23)$. We compared effects of this variant to that of PNPLA3-I148M (Figure 5). In keeping with previous data (5-8,23), TM6SF2-E167K was associated with lower VLDL particle concentrations and TGs in VLDL and LDL, and with a trend for lower cholesterol content in these lipoproteins as well as for lower apoB concentrations (Figure 5). The E167K variant exerted a significant effect in the "High HOMA-IR" but not the "Low HOMA-IR" group (Figure 5). This finding is novel for the TM6SF2-E167K variant and resembles the impact of the variant on IHTG content, which is amplified by adiposity (25). Consistent with these data, apoB secretion has been found to be impaired in variant allele carriers $(7,11)$ and recently in an in vitro disease model using organoids $(48)$. Notably, there appears to be a dissociation between human pathology and the Tm6sf2 knock-out mouse model, in which particle lipidation is decreased but apoB secretion unchanged (49).

In subjects with IR, both the PNPLA3-I148M and TM6SF2-E167K variants seemed to have an approximately equal effect to decrease VLDL particles and VLDL-TG (Figure 5). Consistent with previous reports in Europeans and Finns, 39\% and 7\% of the study participants were hetero- vs. homozygous carriers of the PNPLA3-I148M variant, and 13\% and 1\% of the TM6SF2-E167K variant, respectively $(5,12,14)$. These data imply that the TG-lowering effect of PNPLA3-I148M is more prevalent than that of TM6SF2-E167K. However, whether PNPLA3-I148M and TM6SF2-E167K confer an equal antiatherogenic effect is unclear, as the E167K variant regulates intestinal lipoprotein metabolism $(8,50)$ in addition to hepatic lipoprotein metabolism, and possibly also alters cholesterol metabolism $(8,51)$ in an antiatherogenic fashion.

Of interest, it has recently been shown that rare loss-of-function mutations in the $A P O B$ gene confer an increased risk for hepatocellular carcinoma (52). Carriers of these mutations have a decreased hepatic production of the functional apoB protein and consequently develop severe hepatic 
steatosis, low plasma cholesterol concentrations and are markedly protected against atherosclerotic CVD (53). Thus, $A P O B$ mutations seem to confer similar albeit a more pronounced phenotype compared to that caused by the common NAFLD risk alleles in PNPLA3 and TM6SF2, corroborating the notion that hepatic lipid retention plays a key role in causing NAFLD and its subsequent complications.

We did not exclude patients on lipid lowering therapies from this study, as dyslipidemias are highly prevalent in morbidly obese and insulin-resistant patients. This is an important limitation, as the use of statins may affect NMR analysis of circulating lipids. There were no significant differences in the use of statins between the patient subgroups. Moreover, the effect of genetic variants on lipoproteins was apparent even after excluding statin users in the HOMA-IR subgroup analysis (Figure 5).

The finding that silencing of PNPLA3 expression ameliorates steatosis in rodents has prompted the development of pharmaceuticals aimed at reducing levels of PNPLA3 in the liver (54-56). As PNPLA3I148M may in fact be protective against CVD in insulin-resistant patients with NAFLD - who presumably would be the main candidates for novel therapeutics - the question arises whether blocking of the protein entirely could result in augmented hepatic VLDL secretion, leading to increased levels of circulating lipoproteins and worsening or onset of atherogenic dyslipidemia. Given that such therapies eventually progress to prospective clinical trials, it should be closely monitored whether this happens and if the effect on lipids is transient of permanent.

The emerging evidence that common genetic risk factors, especially the PNPLA3 and TM6SF2 variants, dissociate liver and cardiovascular outcomes may have implications for guidelines and the 
clinic. At present, genotyping of the PNPLA3-I148M and TM6SF2-E167K variants is only recommended in selected patients and in clinical studies (57). Measurement of HOMA-IR is not systematically recommended but could help in identifying those at risk of progressive liver disease (57). The present data show that insulin-resistant carriers of the PNPLA3-I148M variant may have much better lipid profiles than would be anticipated based on IR alone. Therefore, for example in tertiary centers treating morbidly obese patients, genotyping of these variants might prove useful in distinguishing those who need closer liver-related follow-up from those in whom more aggressive treatment of cardiovascular risk factors is required. Alternatively, lack of atherogenic dyslipidemia in routinely assessed lipids in an insulin-resistant patient may be a hint of a greater risk of liver disease, especially in cases where HOMA-IR is above 4 which we demonstrated to be the threshold-level for PNPLA3-I148M effect. This finding underlines the future challenges of personalized medicine, as clinicians and predictive models will have to account for increasingly complex genotype-phenotype interactions. 


\section{ACKNOWLEDGEMENTS}

We gratefully acknowledge volunteers for their help. We thank Aila Karioja-Kallio and Päivi Ihamuotila for their excellent technical assistance.

\section{DATA AVAILABILITY}

The datasets generated during and/or analyzed during the current study are not publicly available but are available from the corresponding author on reasonable request. 


\section{REFERENCES}

1. Younossi ZM, Golabi P, de Avila L, Paik JM, Srishord M, Fukui N, Qiu Y, Burns L, Afendy A, Nader F. The global epidemiology of NAFLD and NASH in patients with type 2 diabetes: A systematic review and meta-analysis. J Hepatol. 2019;71(4):793-801.

2. Yki-Jarvinen $\mathrm{H}$. Non-alcoholic fatty liver disease as a cause and a consequence of metabolic syndrome. Lancet Diabetes Endocrinol. 2014;2(11):901-910.

3. Tchernof A, Despres JP. Pathophysiology of human visceral obesity: an update. Physiol Rev. 2013;93(1):359-404.

4. Brouwers MCGJ, Simons N, Stehouwer CDA, Koek GH, Schaper NC, Isaacs A. Relationship Between Nonalcoholic Fatty Liver Disease Susceptibility Genes and Coronary Artery Disease. Hepatology Communications. 2019;3(4):587-596.

5. Kozlitina J, Smagris E, Stender S, Nordestgaard BG, Zhou HH, Tybjaerg-Hansen A, Vogt TF, Hobbs HH, Cohen JC. Exome-wide association study identifies a TM6SF2 variant that confers susceptibility to nonalcoholic fatty liver disease. Nat Genet. 2014;46(4):352-356.

6. Zhou Y, Llaurado G, Oresic M, Hyotylainen T, Orho-Melander M, Yki-Jarvinen H. Circulating triacylglycerol signatures and insulin sensitivity in NAFLD associated with the E167K variant in TM6SF2. J Hepatol. 2015;62(3):657-663.

7. Dongiovanni P, Petta S, Maglio C, Fracanzani AL, Pipitone R, Mozzi E, Motta BM, Kaminska D, Rametta R, Grimaudo S, Pelusi S, Montalcini T, Alisi A, Maggioni M, Karja V, Boren J, Kakela P, Di Marco V, Xing C, Nobili V, Dallapiccola B, Craxi A, Pihlajamaki J, Fargion S, Sjostrom L, Carlsson LM, Romeo S, Valenti L. Transmembrane 6 superfamily member 2 gene variant disentangles nonalcoholic steatohepatitis from cardiovascular disease. Hepatology. 2015;61(2):506-514. 
8. O'Hare EA, Yang R, Yerges-Armstrong LM, Sreenivasan U, McFarland R, Leitch CC, Wilson MH, Narina S, Gorden A, Ryan KA, Shuldiner AR, Farber SA, Wood GC, Still CD, Gerhard GS, Robishaw JD, Sztalryd C, Zaghloul NA. TM6SF2 rs58542926 impacts lipid processing in liver and small intestine. Hepatology. 2017;65(5):1526-1542.

9. Holmen OL, Zhang H, Fan Y, Hovelson DH, Schmidt EM, Zhou W, Guo Y, Zhang J, Langhammer A, Lochen ML, Ganesh SK, Vatten L, Skorpen F, Dalen H, Zhang J, Pennathur S, Chen J, Platou C, Mathiesen EB, Wilsgaard T, Njolstad I, Boehnke M, Chen YE, Abecasis GR, Hveem K, Willer CJ. Systematic evaluation of coding variation identifies a candidate causal variant in TM6SF2 influencing total cholesterol and myocardial infarction risk. Nat Genet. 2014;46(4):345-351.

10. Pirola CJ, Sookoian S. The dual and opposite role of the TM6SF2-rs58542926 variant in protecting against cardiovascular disease and conferring risk for nonalcoholic fatty liver: A meta-analysis. Hepatology. 2015;62(6):1742-1756.

11. Kim DS, Jackson AU, Li YK, Stringham HM, FinMetSeq I, Kuusisto J, Kangas AJ, Soininen P, AlaKorpela M, Burant CF, Salomaa V, Boehnke M, Laakso M, Speliotes EK. Novel association of TM6SF2 rs58542926 genotype with increased serum tyrosine levels and decreased apoB100 particles in Finns. J Lipid Res. 2017;58(7):1471-1481.

12. Hyysalo J, Mannisto VT, Zhou Y, Arola J, Karja V, Leivonen M, Juuti A, Jaser N, Lallukka S, Kakela P, Venesmaa S, Simonen M, Saltevo J, Moilanen L, Korpi-Hyovalti E, KeinanenKiukaanniemi S, Oksa H, Orho-Melander M, Valenti L, Fargion S, Pihlajamaki J, Peltonen M, Yki-Jarvinen H. A population-based study on the prevalence of NASH using scores validated against liver histology. J Hepatol. 2014;60(4):839-846. 
13. Romeo S, Sentinelli F, Cambuli VM, Incani M, Congiu T, Matta V, Pilia S, Huang-Doran I, Cossu E, Loche S, Baroni MG. The 148M allele of the PNPLA3 gene is associated with indices of liver damage early in life. J Hepatol. 2010;53(2):335-338.

14. Romeo S, Kozlitina J, Xing C, Pertsemlidis A, Cox D, Pennacchio LA, Boerwinkle E, Cohen JC, Hobbs HH. Genetic variation in PNPLA3 confers susceptibility to nonalcoholic fatty liver disease. Nat Genet. 2008;40(12):1461-1465.

15. Sookoian S, Pirola CJ. Meta-analysis of the influence of I148M variant of patatin-like phospholipase domain containing 3 gene (PNPLA3) on the susceptibility and histological severity of nonalcoholic fatty liver disease. Hepatology. 2011;53(6):1883-1894.

16. Luukkonen PK, Zhou Y, Sadevirta S, Leivonen M, Arola J, Oresic M, Hyotylainen T, YkiJarvinen $\mathrm{H}$. Hepatic ceramides dissociate steatosis and insulin resistance in patients with non-alcoholic fatty liver disease. J Hepatol. 2016;64(5):1167-1175.

17. Liu DJ, Peloso GM, Yu H, Butterworth AS, Wang X, Mahajan A, Saleheen D, Emdin C, Alam D, Alves AC, Amouyel P, Di Angelantonio E, Arveiler D, Assimes TL, Auer PL, Baber U, Ballantyne CM, Bang LE, Benn M, Bis JC, Boehnke M, Boerwinkle E, Bork-Jensen J, Bottinger EP, Brandslund I, Brown M, Busonero F, Caulfield MJ, Chambers JC, Chasman DI, Chen YE, Chen YI, Chowdhury R, Christensen C, Chu AY, Connell JM, Cucca F, Cupples LA, Damrauer SM, Davies G, Deary IJ, Dedoussis G, Denny JC, Dominiczak A, Dube MP, Ebeling T, Eiriksdottir G, Esko T, Farmaki AE, Feitosa MF, Ferrario M, Ferrieres J, Ford I, Fornage M, Franks PW, Frayling TM, Frikke-Schmidt R, Fritsche LG, Frossard P, Fuster V, Ganesh SK, Gao W, Garcia ME, Gieger C, Giulianini F, Goodarzi MO, Grallert H, Grarup N, Groop L, Grove ML, Gudnason V, Hansen T, Harris TB, Hayward C, Hirschhorn JN, Holmen OL, Huffman J, Huo Y, Hveem K, Jabeen S, Jackson AU, Jakobsdottir J, Jarvelin MR, Jensen GB, Jorgensen ME, Jukema JW, Justesen JM, Kamstrup PR, Kanoni S, Karpe F, Kee F, Khera AV, Klarin D, Koistinen HA, 
Kooner JS, Kooperberg C, Kuulasmaa K, Kuusisto J, Laakso M, Lakka T, Langenberg C, Langsted A, Launer $\amalg$, Lauritzen T, Liewald DCM, Lin LA, Linneberg A, Loos RJF, Lu Y, Lu X, Magi R, Malarstig A, Manichaikul A, Manning AK, Mantyselka P, Marouli E, Masca NGD, Maschio A, Meigs JB, Melander O, Metspalu A, Morris AP, Morrison AC, Mulas A, MullerNurasyid M, Munroe PB, Neville MJ, Nielsen JB, Nielsen SF, Nordestgaard BG, Ordovas JM, Mehran R, O'Donnell CJ, Orho-Melander M, Molony CM, Muntendam P, Padmanabhan S, Palmer CNA, Pasko D, Patel AP, Pedersen O, Perola M, Peters A, Pisinger C, Pistis G, Polasek O, Poulter N, Psaty BM, Rader DJ, Rasheed A, Rauramaa R, Reilly DF, Reiner AP, Renstrom F, Rich SS, Ridker PM, Rioux JD, Robertson NR, Roden DM, Rotter JI, Rudan I, Salomaa V, Samani NJ, Sanna S, Sattar N, Schmidt EM, Scott RA, Sever P, Sevilla RS, Shaffer CM, Sim X, Sivapalaratnam S, Small KS, Smith AV, Smith BH, Somayajula S, Southam L, Spector TD, Speliotes EK, Starr JM, Stirrups KE, Stitziel N, Strauch K, Stringham HM, Surendran P, Tada H, Tall AR, Tang H, Tardif JC, Taylor KD, Trompet S, Tsao PS, Tuomilehto J, Tybjaerg-Hansen A, van Zuydam NR, Varbo A, Varga TV, Virtamo J, Waldenberger M, Wang N, Wareham NJ, Warren HR, Weeke PE, Weinstock J, Wessel J, Wilson JG, Wilson PWF, Xu M, Yaghootkar H, Young R, Zeggini E, Zhang H, Zheng NS, Zhang W, Zhang Y, Zhou W, Zhou Y, Zoledziewska M, Charge Diabetes Working G, Consortium EP-I, Consortium E-C, Consortium G, Program VAMV, Howson JMM, Danesh J, McCarthy MI, Cowan CA, Abecasis G, Deloukas P, Musunuru K, Willer CJ, Kathiresan S. Exome-wide association study of plasma lipids in >300,000 individuals. Nat Genet. 2017;49(12):1758-1766.

18. Simons N, Isaacs A, Koek GH, Kuc S, Schaper NC, Brouwers M. PNPLA3, TM6SF2, and MBOAT7 Genotypes and Coronary Artery Disease. Gastroenterology. 2017;152(4):912-913.

19. Meffert PJ, Repp KD, Volzke H, Weiss FU, Homuth G, Kuhn JP, Lerch MM, Aghdassi AA. The PNPLA3 SNP rs738409:G allele is associated with increased liver disease-associated 
mortality but reduced overall mortality in a population-based cohort. J Hepatol. 2018;68(4):858-860.

20. Mitsche MA, Hobbs HH, Cohen JC. Patatin-like phospholipase domain-containing protein 3 promotes transfer of essential fatty acids from triglycerides to phospholipids in hepatic lipid droplets. J Biol Chem. 2018;293(18):6958-6968.

21. Luukkonen PK, Nick A, Holtta-Vuori M, Thiele C, Isokuortti E, Lallukka-Bruck S, Zhou Y, Hakkarainen A, Lundbom N, Peltonen M, Orho-Melander M, Oresic M, Hyotylainen T, Hodson L, Ikonen E, Yki-Jarvinen H. Human PNPLA3-I148M variant increases hepatic retention of polyunsaturated fatty acids. JCI Insight. 2019;4(16).

22. van der Veen JN, Kennelly JP, Wan S, Vance JE, Vance DE, Jacobs RL. The critical role of phosphatidylcholine and phosphatidylethanolamine metabolism in health and disease. Biochim Biophys Acta Biomembr. 2017;1859(9 Pt B):1558-1572.

23. Sliz E, Sebert S, Wurtz P, Kangas AJ, Soininen P, Lehtimaki T, Kahonen M, Viikari J, Mannikko M, Ala-Korpela M, Raitakari OT, Kettunen J. NAFLD risk alleles in PNPLA3, TM6SF2, GCKR and LYPLAL1 show divergent metabolic effects. Hum Mol Genet. 2018;27(12):2214-2223.

24. Jiang ZG, Tapper EB, Kim M, Connelly MA, Krawczyk SA, Yee EU, Herman MA, Mukamal KJ, Lai M. Genetic Determinants of Circulating Lipoproteins in Nonalcoholic Fatty Liver Disease. J Clin Gastroenterol. 2018;52(5):444-451.

25. Stender S, Kozlitina J, Nordestgaard BG, Tybjaerg-Hansen A, Hobbs HH, Cohen JC. Adiposity amplifies the genetic risk of fatty liver disease conferred by multiple loci. Nat Genet. $2017 ; 49(6): 842-847$

26. Barata L, Feitosa MF, Bielak LF, Halligan B, Baldridge AS, Guo X, Yerges-Armstrong LM, Smith AV, Yao J, Palmer ND, VanWagner LB, Carr JJ, Chen Y-DI, Allison M, Budoff MJ, Handelman SK, Kardia SLR, Mosley Jr. TH, Ryan K, Harris TB, Launer LJ, Gudnason V, Rotter JI, Fornage M, 
Rasmussen-Torvik LJ, Borecki IB, O’Connell JR, Peyser PA, Speliotes EK, Province MA. Insulin Resistance Exacerbates Genetic Predisposition to Nonalcoholic Fatty Liver Disease in Individuals Without Diabetes. Hepatology Communications. 2019;3(7):894-907.

27. Luukkonen PK, Dufour S, Lyu K, Zhang XM, Hakkarainen A, Lehtimaki TE, Cline GW, Petersen KF, Shulman Gl, Yki-Jarvinen H. Effect of a ketogenic diet on hepatic steatosis and hepatic mitochondrial metabolism in nonalcoholic fatty liver disease. Proc Natl Acad Sci U S A. 2020;117(13):7347-7354.

28. Mancina RM, Dongiovanni P, Petta S, Pingitore P, Meroni M, Rametta R, Boren J, Montalcini T, Pujia A, Wiklund O, Hindy G, Spagnuolo R, Motta BM, Pipitone RM, Craxi A, Fargion S, Nobili V, Kakela P, Karja V, Mannisto V, Pihlajamaki J, Reilly DF, Castro-Perez J, Kozlitina J, Valenti L, Romeo S. The MBOAT7-TMC4 Variant rs641738 Increases Risk of Nonalcoholic Fatty Liver Disease in Individuals of European Descent. Gastroenterology. 2016;150(5):12191230 e1216.

29. Abul-Husn NS, Cheng X, Li AH, Xin Y, Schurmann C, Stevis P, Liu Y, Kozlitina J, Stender S, Wood GC, Stepanchick AN, Still MD, McCarthy S, O'Dushlaine C, Packer JS, Balasubramanian S, Gosalia N, Esopi D, Kim SY, Mukherjee S, Lopez AE, Fuller ED, Penn J, Chu X, Luo JZ, Mirshahi UL, Carey DJ, Still CD, Feldman MD, Small A, Damrauer SM, Rader DJ, Zambrowicz B, Olson W, Murphy AJ, Borecki IB, Shuldiner AR, Reid JG, Overton JD, Yancopoulos GD, Hobbs HH, Cohen JC, Gottesman O, Teslovich TM, Baras A, Mirshahi T, Gromada J, Dewey FE. A Protein-Truncating HSD17B13 Variant and Protection from Chronic Liver Disease. N Engl J Med. 2018;378(12):1096-1106.

30. Luukkonen PK, Zhou Y, Hyotylainen T, Leivonen M, Arola J, Orho-Melander M, Oresic M, YkiJarvinen $\mathrm{H}$. The MBOAT7 variant rs641738 alters hepatic phosphatidylinositols and increases severity of non-alcoholic fatty liver disease in humans. J Hepatol. 2016;65(6):1263-1265. 
31. Luukkonen PK, Zhou Y, Nidhina Haridas PA, Dwivedi OP, Hyotylainen T, Ali A, Juuti A, Leivonen M, Tukiainen T, Ahonen L, Scott E, Palmer JM, Arola J, Orho-Melander M, Vikman P, Anstee QM, Olkkonen VM, Oresic M, Groop L, Yki-Jarvinen H. Impaired hepatic lipid synthesis from polyunsaturated fatty acids in TM6SF2 E167K variant carriers with NAFLD. J Hepatol. 2017;67(1):128-136.

32. Luukkonen PK, Tukiainen T, Juuti A, Sammalkorpi H, Haridas PAN, Niemela O, Arola J, OrhoMelander M, Hakkarainen A, Kovanen PT, Dwivedi O, Groop L, Hodson L, Gastaldelli A, Hyotylainen T, Oresic M, Yki-Jarvinen $\mathrm{H}$. Hydroxysteroid 17-beta dehydrogenase 13 variant increases phospholipids and protects against fibrosis in nonalcoholic fatty liver disease. $\mathrm{JCI}$ Insight. 2020;5(5).

33. Bedossa P, Poitou C, Veyrie N, Bouillot JL, Basdevant A, Paradis V, Tordjman J, Clement K. Histopathological algorithm and scoring system for evaluation of liver lesions in morbidly obese patients. Hepatology. 2012;56(5):1751-1759.

34. Matthews DR, Hosker JP, Rudenski AS, Naylor BA, Treacher DF, Turner RC. Homeostasis model assessment: insulin resistance and beta-cell function from fasting plasma glucose and insulin concentrations in man. Diabetologia. 1985;28(7):412-419.

35. Isokuortti E, Zhou Y, Peltonen M, Bugianesi E, Clement K, Bonnefont-Rousselot D, Lacorte JM, Gastaldelli A, Schuppan D, Schattenberg JM. Use of HOMA-IR to diagnose non-alcoholic fatty liver disease: a population-based and inter-laboratory study. Diabetologia. 2017;60(10):1873-1882.

36. Wurtz P, Kangas AJ, Soininen P, Lawlor DA, Davey Smith G, Ala-Korpela M. Quantitative Serum Nuclear Magnetic Resonance Metabolomics in Large-Scale Epidemiology: A Primer on -Omic Technologies. Am J Epidemiol. 2017;186(9):1084-1096. 
37. Stefan D, Di Cesare F, Andrasescu A, Popa E, Lazariev A, Vescovo E, Strbak O, Williams S, Starcuk Z, Cabanas M. Quantitation of magnetic resonance spectroscopy signals: the jMRUI software package. Measurement Science and Technology. 2009;20(10):104035.

38. Vanhamme L, van den Boogaart A, Van Huffel S. Improved method for accurate and efficient quantification of MRS data with use of prior knowledge. Journal of magnetic resonance. 1997;129(1):35-43.

39. Longo R, Pollesello P, Ricci C, Masutti F, Kvam BJ, Bercich L, Croce LS, Grigolato P, Paoletti S, de Bernard B, et al. Proton MR spectroscopy in quantitative in vivo determination of fat content in human liver steatosis. J Magn Reson Imaging. 1995;5(3):281-285.

40. Szczepaniak LS, Babcock EE, Schick F, Dobbins RL, Garg A, Burns DK, McGarry JD, Stein DT. Measurement of intracellular triglyceride stores by $\mathrm{H}$ spectroscopy: validation in vivo. Am J Physiol. 1999;276(5):E977-989.

41. Lomonaco R, Ortiz-Lopez C, Orsak B, Webb A, Hardies J, Darland C, Finch J, Gastaldelli A, Harrison S, Tio F. Effect of adipose tissue insulin resistance on metabolic parameters and liver histology in obese patients with nonalcoholic fatty liver disease. Hepatology. 2012;55(5):1389-1397.

42. Stekhoven DJ, Buhlmann P. MissForest--non-parametric missing value imputation for mixedtype data. Bioinformatics. 2012;28(1):112-118.

43. Kokla M, Virtanen J, Kolehmainen M, Paananen J, Hanhineva K. Random forest-based imputation outperforms other methods for imputing LC-MS metabolomics data: a comparative study. BMC Bioinformatics. 2019;20(1):492.

44. Szczepaniak LS, Nurenberg P, Leonard D, Browning JD, Reingold JS, Grundy S, Hobbs HH, Dobbins RL. Magnetic resonance spectroscopy to measure hepatic triglyceride content: 
prevalence of hepatic steatosis in the general population. Am J Physiol Endocrinol Metab. 2005;288(2):E462-468.

45. Palmer CN, Maglio C, Pirazzi C, Burza MA, Adiels M, Burch L, Donnelly LA, Colhoun H, Doney AS, Dillon JF, Pearson ER, McCarthy M, Hattersley AT, Frayling T, Morris AD, Peltonen M, Svensson PA, Jacobson P, Boren J, Sjostrom L, Carlsson LM, Romeo S. Paradoxical lower serum triglyceride levels and higher type 2 diabetes mellitus susceptibility in obese individuals with the PNPLA3 148M variant. PLoS One. 2012;7(6):e39362.

46. Pirazzi C, Adiels M, Burza MA, Mancina RM, Levin M, Stahlman M, Taskinen MR, OrhoMelander M, Perman J, Pujia A, Andersson L, Maglio C, Montalcini T, Wiklund O, Boren J, Romeo S. Patatin-like phospholipase domain-containing 3 (PNPLA3) I148M (rs738409) affects hepatic VLDL secretion in humans and in vitro. J Hepatol. 2012;57(6):1276-1282.

47. Mahdessian H, Taxiarchis A, Popov S, Silveira A, Franco-Cereceda A, Hamsten A, Eriksson P, van't Hooft F. TM6SF2 is a regulator of liver fat metabolism influencing triglyceride secretion and hepatic lipid droplet content. Proc Natl Acad Sci U S A. 2014;111(24):8913-8918.

48. Prill S, Caddeo A, Baselli G, Jamialahmadi O, Dongiovanni P, Rametta R, Kanebratt KP, Pujia A, Pingitore P, Mancina RM, Linden D, Whatling C, Janefeldt A, Kozyra M, IngelmanSundberg M, Valenti L, Andersson TB, Romeo S. The TM6SF2 E167K genetic variant induces lipid biosynthesis and reduces apolipoprotein B secretion in human hepatic 3D spheroids. Sci Rep. 2019;9(1):11585.

49. Smagris E, Gilyard S, BasuRay S, Cohen JC, Hobbs HH. Inactivation of Tm6sf2, a Gene Defective in Fatty Liver Disease, Impairs Lipidation but Not Secretion of Very Low Density Lipoproteins. J Biol Chem. 2016;291(20):10659-10676.

50. Musso G, Cipolla U, Cassader M, Pinach S, Saba F, De Michieli F, Paschetta E, Bongiovanni D, Framarin L, Leone N. TM6SF2 rs58542926 variant affects postprandial lipoprotein 
metabolism and glucose homeostasis in NAFLD. Journal of lipid research. 2017;58(6):12211229.

51. Fan Y, Lu H, Guo Y, Zhu T, Garcia-Barrio MT, Jiang Z, Willer CJ, Zhang J, Chen YE. Hepatic transmembrane 6 superfamily member 2 regulates cholesterol metabolism in mice. Gastroenterology. 2016;150(5):1208-1218.

52. Pelusi S, Baselli G, Pietrelli A, Dongiovanni P, Donati B, McCain MV, Meroni M, Fracanzani AL, Romagnoli R, Petta S, Grieco A, Miele L, Soardo G, Bugianesi E, Fargion S, Aghemo A, D'Ambrosio R, Xing C, Romeo S, De Francesco R, Reeves HL, Valenti LVC. Rare Pathogenic Variants Predispose to Hepatocellular Carcinoma in Nonalcoholic Fatty Liver Disease. Sci Rep. 2019;9(1):3682.

53. Welty FK. Hypobetalipoproteinemia and abetalipoproteinemia: liver disease and cardiovascular disease. Curr Opin Lipidol. 2020;31(2):49-55.

54. BasuRay S, Wang Y, Smagris E, Cohen JC, Hobbs HH. Accumulation of PNPLA3 on lipid droplets is the basis of associated hepatic steatosis. Proc Natl Acad Sci U S A. 2019;116(19):9521-9526.

55. Linden D, Ahnmark A, Pingitore P, Ciociola E, Ahlstedt I, Andreasson AC, Sasidharan K, Madeyski-Bengtson K, Zurek M, Mancina RM, Lindblom A, Bjursell M, Bottcher G, Stahlman M, Bohlooly YM, Haynes WG, Carlsson B, Graham M, Lee R, Murray S, Valenti L, Bhanot S, Akerblad P, Romeo S. Pnpla3 silencing with antisense oligonucleotides ameliorates nonalcoholic steatohepatitis and fibrosis in Pnpla3 I148M knock-in mice. Mol Metab. 2019;22:49-61.

56. Kumashiro N, Yoshimura T, Cantley JL, Majumdar SK, Guebre-Egziabher F, Kursawe R, Vatner DF, Fat I, Kahn M, Erion DM, Zhang XM, Zhang D, Manchem VP, Bhanot S, Gerhard GS, Petersen KF, Cline GW, Samuel VT, Shulman GI. Role of patatin-like phospholipase domain- 
containing 3 on lipid-induced hepatic steatosis and insulin resistance in rats. Hepatology. 2013;57(5):1763-1772.

57. European Association for the Study of the L, European Association for the Study of D, European Association for the Study of O. EASL-EASD-EASO Clinical Practice Guidelines for the management of non-alcoholic fatty liver disease. J Hepatol. 2016;64(6):1388-1402. 


\section{FIGURE LEGENDS}

Figure 1. Lipoprotein TG and cholesterol composition in the Bariatric cohort. Absolute concentrations of TGs (upper panel) and cholesterol (lower panel) in plasma lipoprotein subfractions. Bars represent medians, error bars show $25^{\text {th }}$ to $75^{\text {th }}$ percentiles. $\mathrm{XXL}=$ extremely large, $\mathrm{XL}=\mathrm{very}$ large, $\mathrm{L}=$ large, $\mathrm{M}=$ medium, $\mathrm{S}=$ small, $\mathrm{XS}$ =very small, $\mathrm{VLDL=very-low}$-density lipoprotein, LDL=low-density lipoprotein, IDL=intermediate-density lipoprotein, $\mathrm{HDL}=$ high-density lipoprotein.

Figure 2. Effects of IR and the PNPLA3 rs738409-G allele on circulating lipoproteins in the Bariatric cohort. Differences in absolute concentrations of plasma lipoprotein particle subfractions and their lipid constituents between the groups ("High HOMA-IR" vs. "Low HOMA-IR", panel on the left; "PNPLA3 CG/GG" vs. "PNPLA3 CC", panel in the middle; "PNPLA3 GG" vs. "PNPLA3 CC", panel on the right). Color coding represents the fold change in mean concentrations between the groups. The brighter the red color, the higher the increase in the absolute concentration of a lipoprotein fraction in the "High HOMA-IR" compared to the "Low HOMA-IR" group, "PNPLA3 CG/GG" compared to the "PNPLA3 CC" group, or the "PNPLA3 GG" compared to the "PNPLA3 CC" group. * $P \leq 0.05,{ }^{* *} P \leq 0.01$, ***P $\leq 0.001$. $X X L=$ extremely large, $\mathrm{XL}=$ very large, $\mathrm{L}=$ large, $\mathrm{M}=$ medium, $\mathrm{S}=$ small, $\mathrm{XS}=$ very small, VLDL=very-low-density lipoprotein, $\quad L D L=l o w$-density lipoprotein, IDL=intermediate-density lipoprotein, $\mathrm{HDL}=$ high-density lipoprotein.

Figure 3. Lipoprotein TG and cholesterol composition in the Non-bariatric cohort. Absolute concentrations of TGs (upper panel) and cholesterol (lower panel) in plasma lipoprotein subfractions. Bars represent medians, error bars show $25^{\text {th }}$ to $75^{\text {th }}$ percentiles. $X X L=e x t r e m e l y$ large, $X L=$ very large, $\mathrm{L}=$ large, $\mathrm{M}=$ medium, $\mathrm{S}=$ small, $\mathrm{XS}=$ very small, $\mathrm{VLDL=very-low}$-density lipoprotein, $\mathrm{LDL=low}$-density lipoprotein, IDL=intermediate-density lipoprotein, HDL=high-density lipoprotein. 
Figure 4. Effects of IR and the PNPLA3 rs738409-G allele on circulating lipoproteins in the Non-bariatric cohort. Differences in absolute concentrations of plasma lipoprotein particle subfractions and their lipid constituents between groups ("High HOMA-IR" vs. "Low HOMA-IR", panel on the left; "PNPLA3 GG" vs. "PNPLA3 CC", panel on the right). Color coding represents the fold change in mean concentrations between the groups. The brighter the red color, the higher the increase in the absolute concentration of a lipoprotein fraction in the "High HOMA-IR" compared to the "Low HOMA-IR" group or the "PNPLA3 GG" compared to the "PNPLA3 CC" group. *P $\leq 0.05, * * P \leq 0.01$, ***P $\leq$ 0.001. $\mathrm{XXL}=$ extremely large, $\mathrm{XL}=$ very large, $\mathrm{L}=$ large, $\mathrm{M}=$ medium, $\mathrm{S}=$ small, $\mathrm{XS}=$ very small, VLDL=very-low-density lipoprotein, $L D L=l o w$-density lipoprotein, IDL=intermediate-density lipoprotein, HDL=high-density lipoprotein.

Figure 5. Interaction between IR and NAFLD risk alleles on circulating lipoproteins. Forest plots showing genetic effects of PNPLA3 rs738409-G (first two panels) and TM6SF2 rs58542926-T (last two panels) alleles on circulating lipoprotein concentrations, particle diameters, particle TG content, particle cholesterol content, and apolipoprotein concentrations in "High HOMA-IR" and "Low HOMA-IR" groups separately, in the Bariatric cohort. The binary logistic regression models were adjusted for age, sex, BMI, and smoking status. The $\mathrm{x}$-axis shows the odds ratio per unit change in standard deviation (SD) of a measured variable. Black circles denote statistically significant association and white circles no association. Whiskers denote 95\% confidence intervals ( $\mathrm{Cl})$. XXL=extremely large, $\mathrm{XL}=$ very large, $\mathrm{L}=$ large, $\mathrm{M}=$ medium, $\mathrm{S}=$ small, $\mathrm{XS}=$ very small, $\mathrm{VLDL=very-low}$-density lipoprotein, $\mathrm{LDL=low}$-density lipoprotein, IDL=intermediate-density lipoprotein, $\mathrm{HDL}=$ high-density lipoprotein. 
Figure 6. Effect of PNPLA3 rs738409-G on circulating lipoproteins stratified by HOMA-IR quartiles in the pooled cohort. Forest plots showing genetic effects of the PNPLA3 rs738409-G allele on circulating lipoprotein concentrations, particle diameters, particle TG content, particle cholesterol content, and apoB to apoA-1 ratio in the pooled cohort, stratified by HOMA-IR quartiles (Q1-Q4). Median HOMAIR $\left[25^{\text {th }}-75^{\text {th }}\right.$ percentiles $]$ for each quartile are shown. The binary logistic regression models were adjusted for age, sex, BMI, smoking status, and use of statins. The $x$-axis shows the odds ratio per unit change in standard deviation (SD) of a measured variable. Black circles denote statistically significant association and white circles no association. Whiskers denote $95 \%$ confidence intervals (CI). XXL=extremely large, $\mathrm{XL}=$ very large, $\mathrm{L}=$ large, $\mathrm{M}=$ medium, $\mathrm{S}=$ small, $\mathrm{XS}=$ very small, $\mathrm{VLDL}=$ very-low-

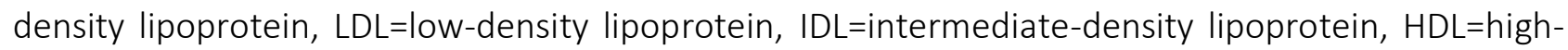
density lipoprotein. 


\section{TABLES}

Table 1. Clinical characteristics of patients in the Bariatric cohort according to sex-specific median HOMA-IR and PNPLA3 rs738409-G allele carrier status.

\begin{tabular}{|c|c|c|c|c|}
\hline & Low HOMA-IR & High HOMA-IR & PNPLA3 CC & PNPLA3 CG/GG \\
\hline Group size, $n$ & 86 & 88 & 174 & 124 \\
\hline Age, years & $48 \pm 9$ & $48 \pm 9$ & $48 \pm 9$ & $49 \pm 9$ \\
\hline Females, n (\%) & $65(76)$ & $65(74)$ & $130(75)$ & $87(70)$ \\
\hline $\mathrm{BMI}, \mathrm{kg} / \mathrm{m}^{2}$ & $40.8 \pm 6.1$ & $44.3 \pm 6.2^{* * *}$ & $42.6 \pm 6.4$ & $44.0 \pm 7.4$ \\
\hline Waist circumference, $\mathrm{cm}$ & $119 \pm 15$ & $130 \pm 15^{* * *}$ & $125 \pm 16$ & $128 \pm 17$ \\
\hline Systolic blood pressure, $\mathrm{mmHg}$ & $132 \pm 16$ & $134 \pm 16$ & $133 \pm 16$ & $135 \pm 15$ \\
\hline Diastolic blood pressure, $\mathrm{mmHg}$ & $84 \pm 10$ & $87 \pm 9$ & $86 \pm 10$ & $88 \pm 12$ \\
\hline $\mathrm{fP}-\mathrm{Glucose}, \mathrm{mmol} / \mathrm{L}$ & $5.4(5.0-5.9)$ & $6.1(5.6-6.9)^{* * *}$ & $5.8(5.2-6.3)$ & $5.9(5.4-6.5)$ \\
\hline $\mathrm{HbA}_{1 \mathrm{c}}, \%$ & $5.6(5.4-5.8)$ & $5.9(5.6-6.4)^{* * *}$ & $5.7(5.4-6.2)$ & $5.8(5.5-6.2)$ \\
\hline fS-Insulin, mU/L & $7.8(5.8-10.5)$ & $18.2(14.4-26.3)^{* * *}$ & $12.2(7.7-18.9)$ & $12.8(8.4-17.9)$ \\
\hline HOMA-IR & $1.9(1.3-2.6)$ & $4.9(3.9-7.0)^{* * *}$ & $3.2(1.9-4.9)$ & $3.5(2.2-5.0)$ \\
\hline fP-Total cholesterol, $\mathrm{mmol} / \mathrm{L}$ & $4.2(3.5-4.8)$ & $4.2(3.7-4.9)$ & $4.2(3.6-4.9)$ & $4.2(3.7-4.8)$ \\
\hline fP-HDL cholesterol, mmol/L & $1.27(1.02-1.50)$ & $1.08(0.93-1.24)^{* * *}$ & $1.14(0.96-1.38)$ & $1.19(0.97-1.43)$ \\
\hline fP-LDL cholesterol, mmol/L & $2.5(2.0-3.1)$ & $2.5(1.9-3.3)$ & $2.5(2.0-3.2)$ & $2.5(1.9-3.0)$ \\
\hline fP-Triglycerides, mmol/L & $1.02(0.77-1.28)$ & $1.40(1.19-1.85)^{* * *}$ & $1.23(0.88-1.61)$ & $1.25(1.00-1.67)$ \\
\hline P-ALT, U/L & $28(20-39)$ & $38(25-50)^{* *}$ & $31(23-47)$ & $34(22-46)$ \\
\hline P-AST, U/L & $26(23-35)$ & $31(25-36)$ & $28(23-36)$ & $30(24-38)$ \\
\hline P-GGT, U/L & $25(17-43)$ & $33(21-55)^{* *}$ & $28(19-50)$ & $33(21-49)$ \\
\hline P-Albumin, $g / L$ & $38(37-40)$ & $39(37-41)$ & $38(37-41)$ & $38(36-40)$ \\
\hline B-Platelets, $10^{9} / \mathrm{L}$ & $239 \pm 59$ & $270 \pm 58^{* * *}$ & $255(60)$ & $255(65)$ \\
\hline IHTG (histology), \% & $0(0-10)$ & $13(5-33)^{* * *}$ & $5(0-20)$ & $15(0-30)^{*}$ \\
\hline NASH, n (\%) & $6(7)$ & $14(17)$ & $14(8)$ & $18(15)$ \\
\hline SAF score & $1.0 \pm 1.5$ & $2.1 \pm 2.0^{* * *}$ & $1.6 \pm 1.9$ & $2.0 \pm 2.0^{*}$ \\
\hline Type 2 diabetes, n (\%) & $23(27)$ & $38(43)^{*}$ & $64(37)$ & $57(46)$ \\
\hline Current cigarette smoking, n (\%) & $17(20)$ & $15(17)$ & $32(18)$ & $24(19)$ \\
\hline Use of antihypertensives, n (\%) & $50(58)$ & $57(65)$ & $107(61)$ & $82(66)$ \\
\hline Use of statins, n (\%) & $22(26)$ & $31(35)$ & $53(30)$ & $35(28)$ \\
\hline Use of thiazolidinediones, $n$ (\%) & $3(3)$ & $3(3)$ & $6(3)$ & $7(6)$ \\
\hline PNPLA3 (CC/CG/GG), $\mathrm{n}$ & $86 / 0 / 0$ & $88 / 0 / 0$ & $174 / 0 / 0$ & $0 / 107 / 17^{* * *}$ \\
\hline TMGSF2 (CC/CT/TT), n & $76 / 10 / 0$ & $77 / 9 / 1$ & $153 / 19 / 1$ & $108 / 15 / 1$ \\
\hline MBOAT7 (CC/CT/TT), n & $27 / 44 / 14$ & 27/39/19 & $54 / 83 / 33$ & $40 / 64 / 20$ \\
\hline HSD17B13 (00/A0/AA), n & $47 / 33 / 4$ & $58 / 24 / 3$ & $105 / 57 / 7$ & $74 / 47 / 3$ \\
\hline
\end{tabular}

Data are in $n(\%)$, mean \pm SD or median $\left(25^{\text {th }}-75^{\text {th }}\right.$ percentiles). Significances were determined by Student's $t$, Mann-Whitney $U$, Chi-squared or Fisher's exact tests. f, fasting; $\mathrm{P}$, plasma; $\mathrm{B}$, blood; IHTG, intrahepatic triglycerides. ${ }^{*} P \leq 0.05,{ }^{* *} P \leq 0.01$, $* * * P \leq 0.001$ 
Table 2. Clinical characteristics of homozygous carriers and non-carriers of the PNPLA3 rs738409-G allele in the Bariatric cohort.

\begin{tabular}{|c|c|c|}
\hline & PNPLA3 CC & PNPLA3 GG \\
\hline Group size, $\mathrm{n}$ & 174 & 17 \\
\hline Age, years & $48 \pm 9$ & $46 \pm 9$ \\
\hline Females, n (\%) & $130(75)$ & $12(71)$ \\
\hline $\mathrm{BMI}, \mathrm{kg} / \mathrm{m}^{2}$ & $42.6 \pm 6.4$ & $41.9 \pm 11.5$ \\
\hline Waist circumference, $\mathrm{cm}$ & $124.9 \pm 15.7$ & $122.4 \pm 23.3$ \\
\hline Systolic blood pressure, $\mathrm{mmHg}$ & $133 \pm 16$ & $136 \pm 15$ \\
\hline Diastolic blood pressure, $\mathrm{mmHg}$ & $86 \pm 9$ & $91 \pm 12$ \\
\hline $\mathrm{fP}-\mathrm{Glucose}, \mathrm{mmol} / \mathrm{L}$ & $5.8(5.2-6.3)$ & $5.6(5.0-6.0)$ \\
\hline $\mathrm{HbA}_{1 \mathrm{c}} \%$ & $5.7(5.4-6.2)$ & $5.7(5.5-6.0)$ \\
\hline fS-Insulin, mU/L & $12.2(7.7-18.9)$ & $12.4(6.0-22.0)$ \\
\hline HOMA-IR & $3.2(1.9-4.5)$ & $3.0(1.5-5.3)$ \\
\hline fP-Total cholesterol, mmol/L & $4.2(3.6-4.9)$ & $4.3(3.6-4.8)$ \\
\hline fP-HDL cholesterol, mmol/L & $1.14(0.96-1.38)$ & $1.23(1.09-1.61)$ \\
\hline fP-LDL cholesterol, mmol/L & $2.5(2.0-3.2)$ & $2.3(2.0-3.0)$ \\
\hline fP-Triglycerides, mmol/L & $1.23(0.88-1.61)$ & $1.12(1.03-1.34)^{*}$ \\
\hline P-ALT, U/L & $31(23-47)$ & $35(22-48)$ \\
\hline P-AST, U/L & $28(23-36)$ & $34(27-50)$ \\
\hline P-GGT, U/L & $28(19-50)$ & $22(19-56)$ \\
\hline P-Albumin, g/L & $38(37-41)$ & $38(36-39)$ \\
\hline B-Platelets, $10^{9} / \mathrm{L}$ & $255 \pm 60$ & $230 \pm 67$ \\
\hline IHTG (histology), \% & $5(0-20)$ & $15(5-20)$ \\
\hline $\mathrm{NASH}, \mathrm{n}(\%)$ & $14(8)$ & $3(18)$ \\
\hline SAF score & $1.6 \pm 1.9$ & $2.6 \pm 2.3^{*}$ \\
\hline Type 2 diabetes, n (\%) & $61(35)$ & $7(41)$ \\
\hline Current cigarette smoking, n (\%) & $32(18)$ & $4(24)$ \\
\hline Use of antihypertensives, n (\%) & $107(61)$ & $10(59)$ \\
\hline Use of statins, n (\%) & $53(30)$ & $4(24)$ \\
\hline Use of thiazolidinediones, n (\%) & $6(3)$ & $0(0)$ \\
\hline PNPLA3 (CC/CG/GG), n & $174 / 0 / 0$ & $0 / 0 / 17^{* * *}$ \\
\hline TM6SF2 (CC/CT/TT), n & $153 / 19 / 1$ & $14 / 3 / 0$ \\
\hline MBOAT7 (CC/CT/TT), n & $54 / 83 / 33$ & $3 / 13 / 1$ \\
\hline HSD17B13 (00/A0/AA), n & $105 / 57 / 7$ & $13 / 4 / 0$ \\
\hline
\end{tabular}

Data are in $n(\%)$, mean \pm SD or median $\left(25^{\text {th }}-75^{\text {th }}\right.$ percentiles). Significances were determined by Student's $t$, Mann-Whitney $U$, Chi-squared or Fisher's exact tests. $f$, fasting; P, plasma; B, blood; IHTG, intrahepatic triglycerides. ${ }^{*} P \leq 0.05,{ }^{*} P \leq 0.01$, $* * * P \leq 0.001$ 
Table 3. Clinical characteristics of volunteers in the Non-bariatric cohort according to sex-specific HOMA-IR and PNPLA3 rs738409-G allele carrier status.

\begin{tabular}{|c|c|c|c|c|}
\hline & LOW HOMA-IR & High HOMA-IR & PNPLA3 CC & PNPLA3 GG \\
\hline Group size, $n$ & 88 & 89 & 177 & 25 \\
\hline Age, years & $41 \pm 13$ & $46 \pm 14^{* *}$ & $43 \pm 14$ & $47 \pm 14$ \\
\hline Females, n (\%) & $50(57)$ & $51(57)$ & $101(57)$ & $17(68)$ \\
\hline $\mathrm{BMI}, \mathrm{kg} / \mathrm{m}^{2}$ & $27.0 \pm 4$ & $32.5 \pm 5^{* * *}$ & $29.8 \pm 5.2$ & $31.3 \pm 7.2$ \\
\hline Waist circumference, cm & $90.3 \pm 10.9$ & $106.4 \pm 11.0^{* * *}$ & $98.4 \pm 13.6$ & $102.2 \pm 16.6$ \\
\hline Systolic blood pressure, $\mathrm{mmHg}$ & $129 \pm 19$ & $135 \pm 19 *$ & $132 \pm 19$ & $131 \pm 22$ \\
\hline Diastolic blood pressure, $\mathrm{mmHg}$ & $82 \pm 14$ & $85 \pm 11$ & $83 \pm 13$ & $86 \pm 10$ \\
\hline fP-Glucose, mmol/L & $5.3(5.0-5.6)$ & $5.8(5.5-6.2)^{* * *}$ & $5.6(5.1-6.0)$ & $5.7(5.1-5.9)$ \\
\hline $\mathrm{HbA}_{1 \mathrm{c}}, \%$ & $5.4(5.3-5.6)$ & $5.8(5.6-6.1)^{* * *}$ & $5.6(5.4-5.9)$ & $5.7(5.3-5.9)$ \\
\hline fS-Insulin, mU/L & $3.9(3.0-5.7)$ & $11.1(9.0-14.5)^{* * *}$ & $7.0(3.9-11.1)$ & $6.5(5.0-10.3)$ \\
\hline HOMA-IR & $0.9(0.7-1.4)$ & $2.9(2.3-3.9)^{* * *}$ & $1.8(0.9-2.9)$ & $1.6(1.2-2.6)$ \\
\hline fP-NEFA, umol/L & 415 (321-568) & $579(433-734)^{* * *}$ & 491 (375-667) & $556(412-600)$ \\
\hline Adipo-IR & $1611(1169-2872)$ & $6666(4661-9605)^{* * *}$ & 3198 (1590-5875) & 3314 (1908-5092) \\
\hline fP-Total cholesterol, $\mathrm{mmol} / \mathrm{L}$ & $4.5(4.0-5.0)$ & $4.9(4.5-5.6)^{* * *}$ & $4.7(4.2-5.3)$ & $5.1(4.2-5.6)$ \\
\hline fP-HDL cholesterol, mmol/L & $1.54(1.29-1.72)$ & $1.27(1.09-1.49)^{* * *}$ & $1.38(1.18-1.66)$ & $1.40(1.23-1.72)$ \\
\hline fP-LDL cholesterol, mmol/L & $2.6(2.2-3.1)$ & $3.1(2.6-3.6)^{* * *}$ & $2.80(2.30-3.40)$ & $3.0(2.1-3.5)$ \\
\hline fP-Triglycerides, mmol/L & $0.84(0.61-1.19)$ & $1.55(1.22-2.07)^{* * *}$ & $1.20(0.78-1.64)$ & $1.22(0.96-1.50)$ \\
\hline P-ALT, U/L & $20(16-28)$ & $33(23-51)^{* * *}$ & $25.50(18-38)$ & $41(23-79)^{* *}$ \\
\hline P-AST, U/L & $25(22-30)$ & $28(24-35)^{* *}$ & $26(22-32)$ & $39(28-53)^{* * *}$ \\
\hline P-GGT, U/L & $18(13-28)$ & $36(19-62)^{* * *}$ & $23(15-43)$ & $27(20-59)$ \\
\hline P-Albumin, $g / L$ & $38(36-40)$ & $39(37-41)$ & $39.10(36.20-40.42)$ & $38(36-40)$ \\
\hline B-Platelets, $10^{9} / \mathrm{L}$ & $234(209-261)$ & $246(203-282)$ & $236(207-278)$ & $240(214-268)$ \\
\hline IHTG $\left({ }^{1} \mathrm{H}-\mathrm{MRS}\right), \%$ & $1.0(0.4-2.2)$ & $5.4(2.9-10.7)^{* * *}$ & $2.7(0.8-6.1)$ & $9.1(4.3-13.1)^{* * *}$ \\
\hline Type 2 diabetes, n (\%) & $4(5)$ & $12(13)$ & $16(9)$ & $2(8)$ \\
\hline Current cigarette smoking, n (\%) & $21(24)$ & $14(16)$ & $35(20)$ & $6(24)$ \\
\hline Use of antihypertensives, n (\%) & $12(14)$ & $27(30)^{* *}$ & $39(22)$ & $7(28)$ \\
\hline Use of statins, n (\%) & $8(9)$ & $12(13)$ & $20(11)$ & $5(20)$ \\
\hline Use of thiazolidinediones, n (\%) & $0(0)$ & $1(1)$ & $1(1)$ & $1(4)$ \\
\hline PNPLA3 (CC/CG/GG), $\mathrm{n}$ & $88 / 0 / 0$ & $89 / 0 / 0$ & $177 / 0 / 0$ & $0 / 0 / 25^{* * *}$ \\
\hline TM6SF2 (CC/CT/TT), n & $75 / 11 / 1$ & $76 / 9 / 1$ & $151 / 20 / 2$ & $18 / 6 / 0$ \\
\hline MBOAT7 (CC/CT/TT), $\mathrm{n}$ & $33 / 35 / 14$ & $30 / 40 / 10$ & $63 / 75 / 24$ & $6 / 12 / 4$ \\
\hline HSD17B13 (00/A0/AA), n & $45 / 18 / 4$ & $47 / 20 / 4$ & $92 / 38 / 8$ & $11 / 9 / 0$ \\
\hline
\end{tabular}

Data are in $n(\%)$, mean \pm SD or median $\left(25^{\text {th }}-75^{\text {th }}\right.$ percentiles). Significances were determined by Student's $t$, Mann-Whitney $U$, Chisquared or Fisher's exact tests. f, fasting; P, plasma; B, blood; IHTG, intrahepatic triglycerides; ${ }^{1} \mathrm{H}-\mathrm{MRS}$, proton magnetic resonance spectroscopy. ${ }^{*} P \leq 0.05,{ }^{* *} P \leq 0.01,{ }^{* * *} P \leq 0.001$ 
FIGURES

FIGURE 1
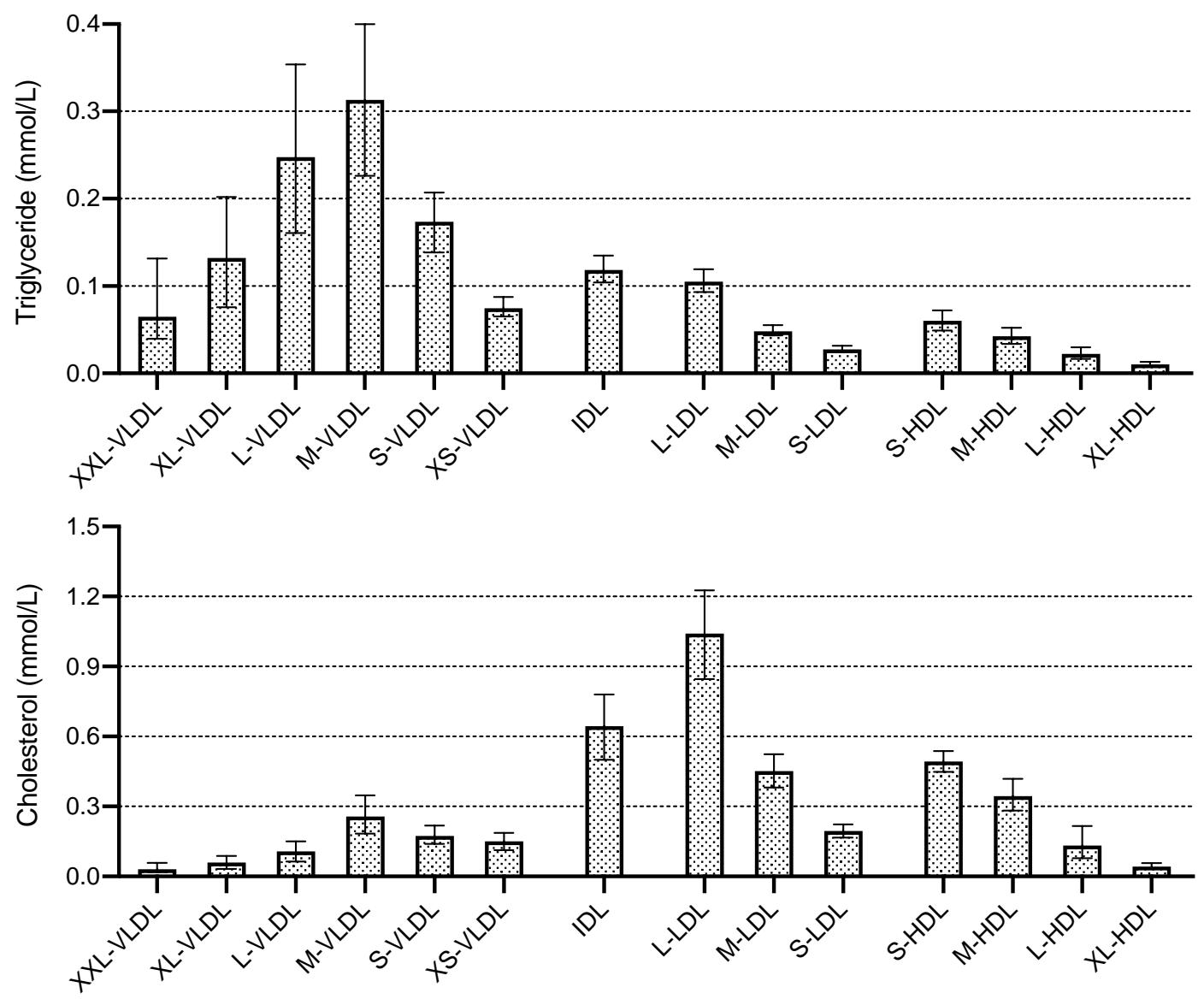


\section{FIGURE 2}

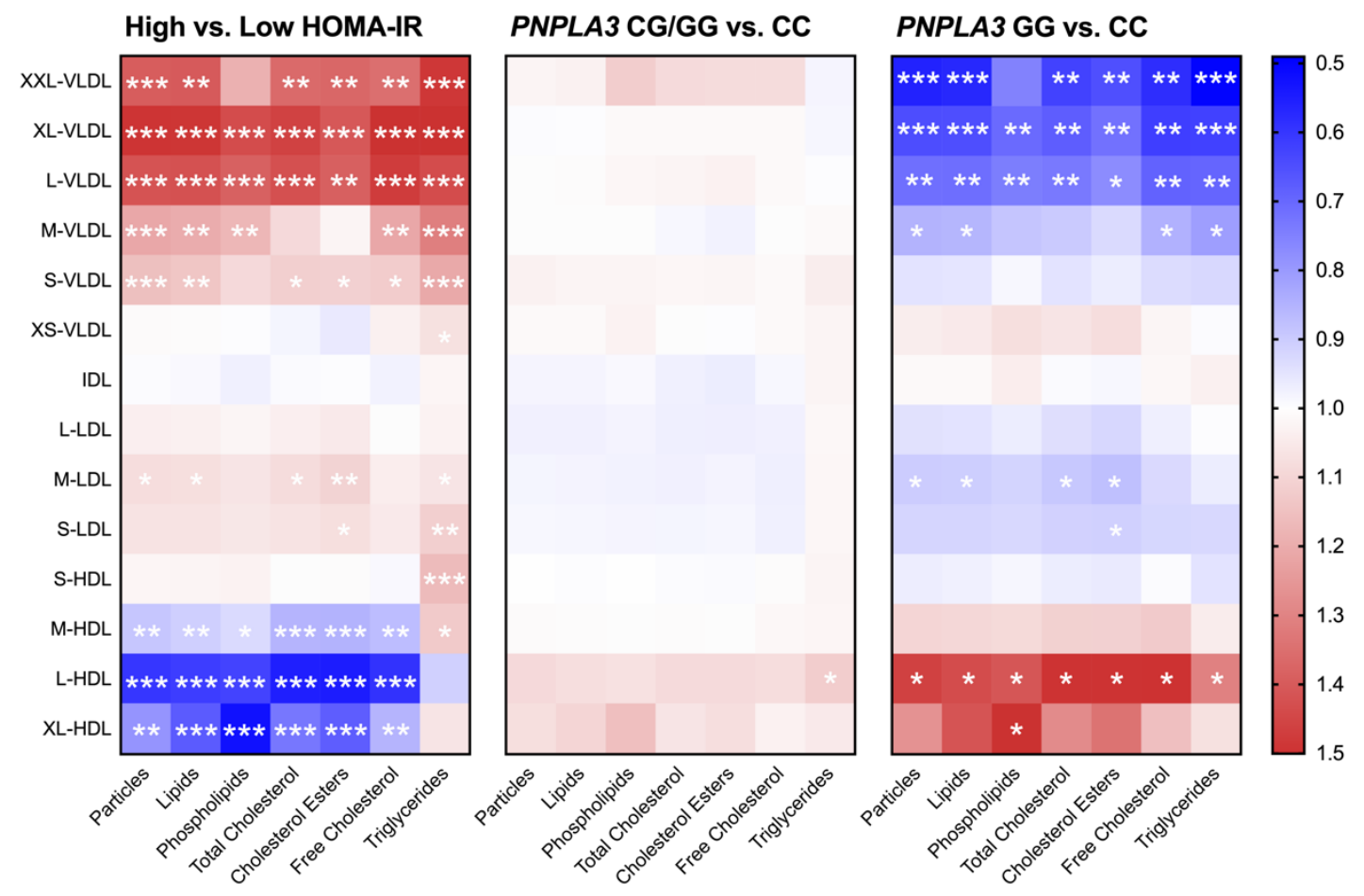


FIGURE 3
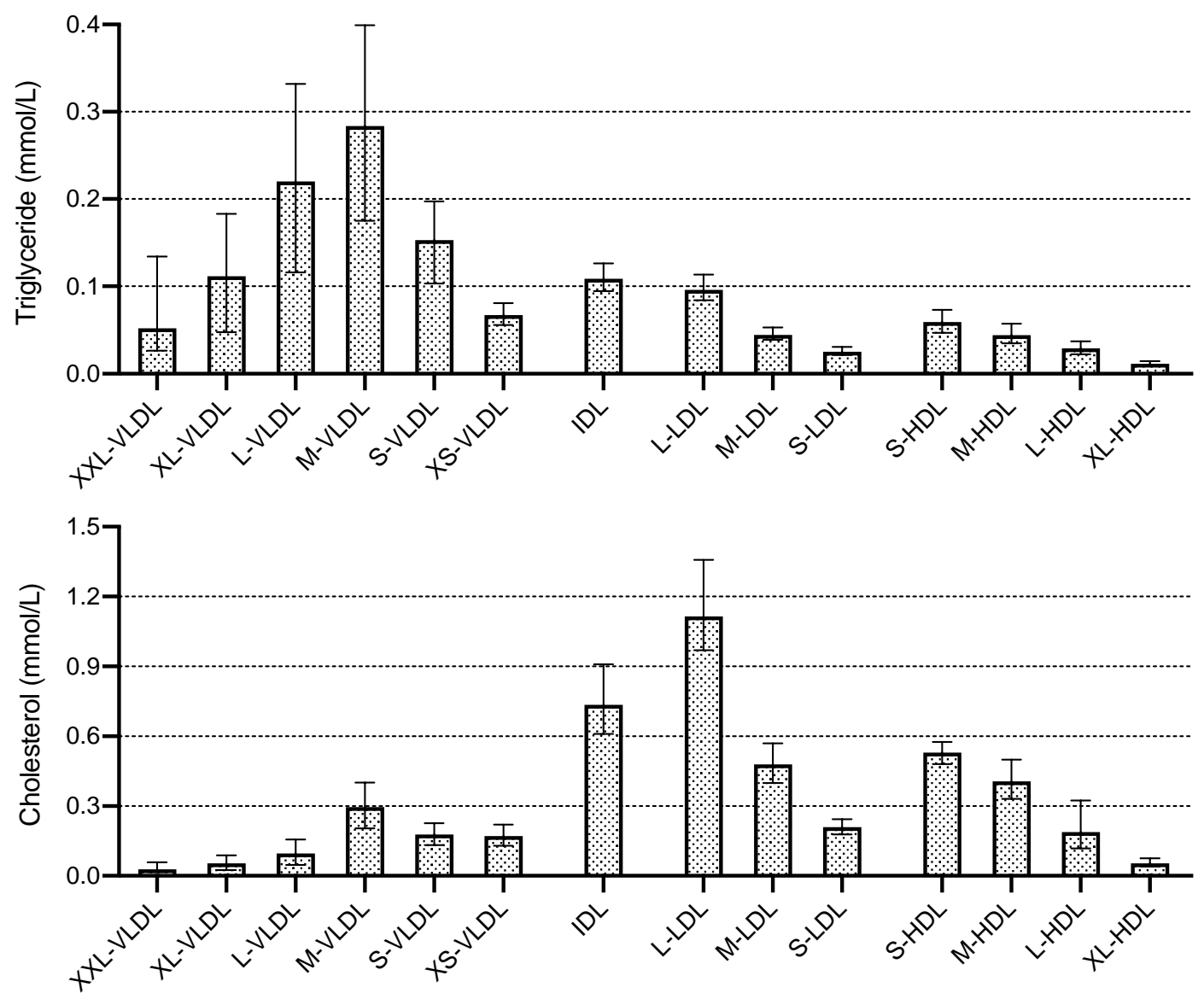
FIGURE 4

High vs. Low HOMA-IR

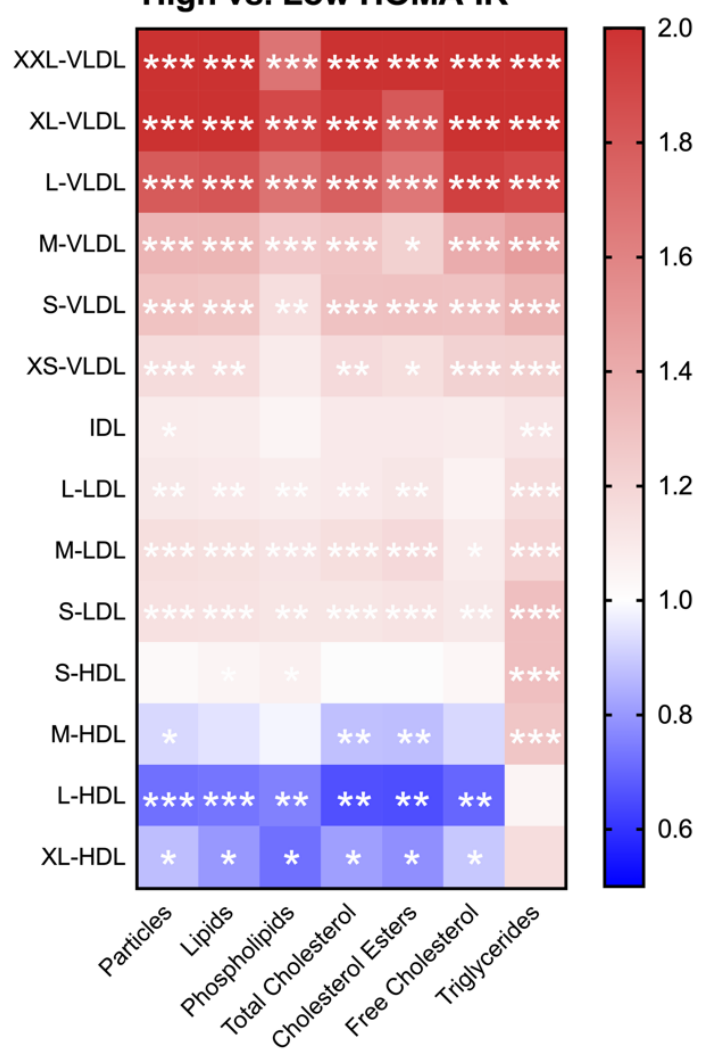

PNPLA3 GG vs. CC

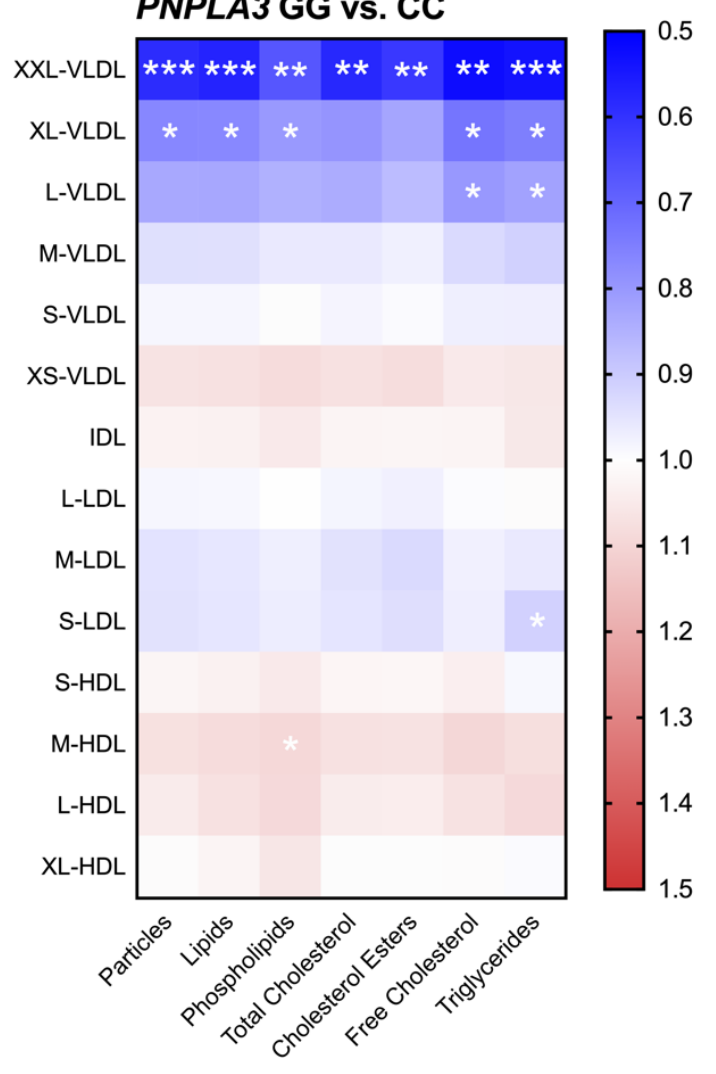


FIGURE 5

PNPLA3 rs738409-G Low HOMA-IR High HOMA-IR

\begin{tabular}{|c|c|}
\hline $\begin{array}{r}\text { Particle concentration } \\
X X L-V L D L\end{array}$ & to \\
\hline XL-VLDL & -o \\
\hline L-VLDL & - \\
\hline M-VLDL & - \\
\hline S-VLDL & -o \\
\hline XS-VLDL & -0 \\
\hline IDL & $-p-$ \\
\hline L-LDL & -0 \\
\hline M-LDL & $-\infty$ \\
\hline S-LDL & $-b$ \\
\hline S-HDL & $-\circ$ \\
\hline M-HDL & -of \\
\hline L-HDL & $-d-$ \\
\hline XL-HDL & $-b$ \\
\hline
\end{tabular}

Particle diameter

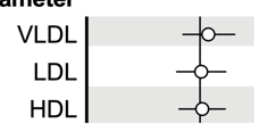

Triglycerides in

$$
\begin{array}{c|c}
\text { VLDL } & \text { to- } \\
\text { LDL } & \text {-o- } \\
\text { HDL } & \text { fo- }
\end{array}
$$

Cholesterol in

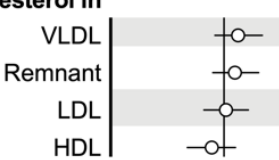

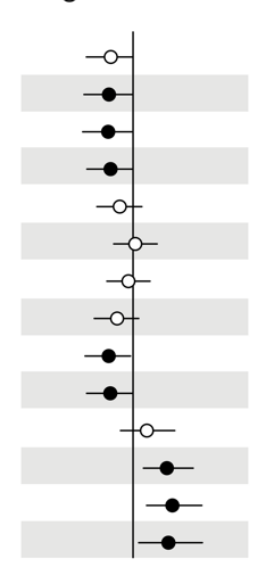
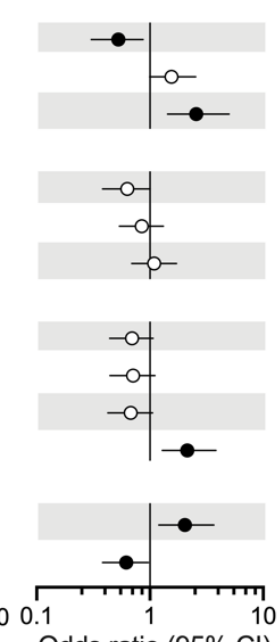

Odds ratio $(95 \% \mathrm{Cl})$ per unit change in $\mathrm{SD}$
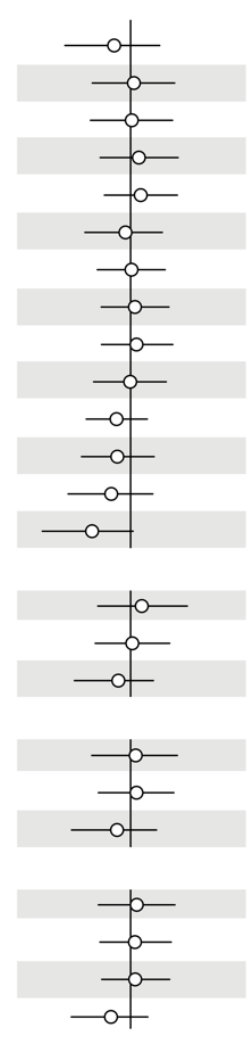

TM6SF2 rs58542926-T

Low HOMA-IR High HOMA-IR
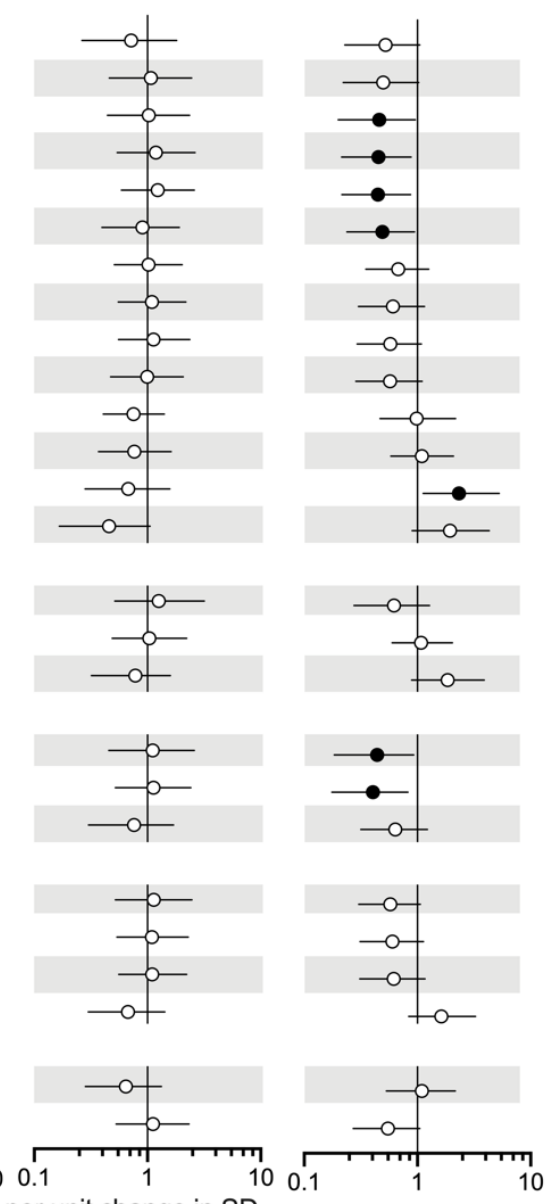
FIGURE 6

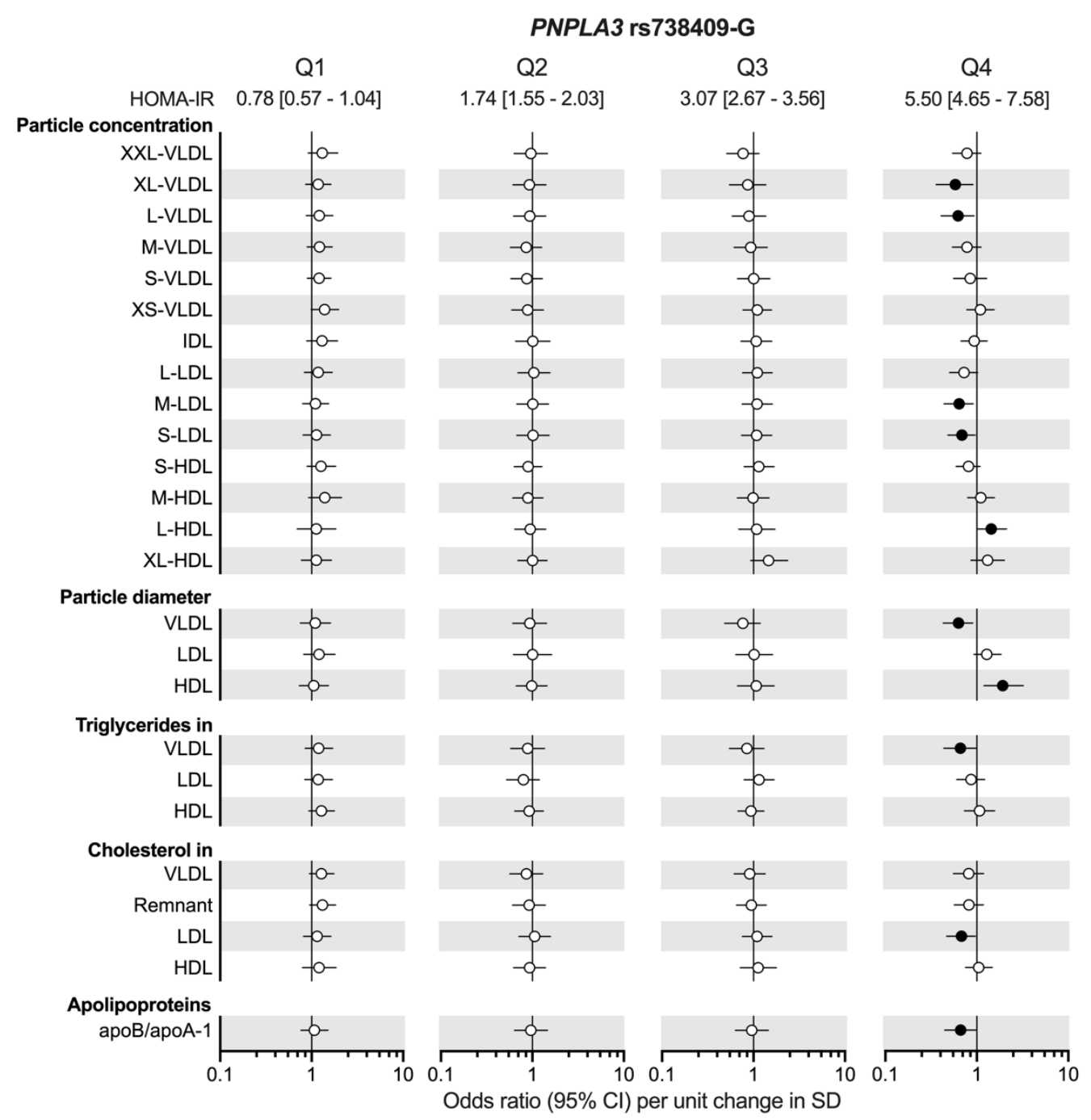

